\title{
Structure and dynamics of useful work along the agriculture-industry-services transition: Portugal from 1856 to 2009
}

\author{
ANDRÉ CABRERA SERRENHO ${ }^{a^{*}}$, BENJAMIN WARR $^{c}$, TÂNIA SOUSA $^{\mathrm{b}}$, ROBERT U. AYRES $^{c}$, TIAGO $^{\circ}$ \\ DOMINGOS ${ }^{\mathrm{b}}$ \\ ${ }^{a}$ Department of Engineering, University of Cambridge, Trumpington Street, Cambridge, CB2 1PZ, United \\ Kingdom. \\ ${ }^{b}$ Maretec, Marine Environmental and Technology Center, Department of Mechanical Engineering, Instituto \\ Superior Técnico, Universidade de Lisboa, Avenida Rovisco Pais, 1, 1049-001 Lisboa, Portugal. \\ ${ }^{c}$ INSEAD, Boulevard de Constance, 77305 Fontainebleau, France. \\ *Corresponding author, e-mail: $\underline{\text { ag806@cam.ac.uk }}$
}

\begin{abstract}
Unlike conventional energy analyses, exergy analysis considers the quality of energy flows and efficiencies in their conversion. Additionally, conventional energy analyses focus on the primary and final stages of energy flows, and do not capture the last stage of energy transformations to useful enduses. We further develop previous useful work accounting methodologies by considering the sectoral breakdown of electricity end-uses and efficiencies. Also, this paper is the first accounting for useful work covering a full agricultural-industrial-services economic transition, taking Portugal 1856-2009. Portuguese aggregate final-to-useful efficiency remains constant until 1920, slightly increases between 1920-1950 due to heating uses, soars between 1950-1980 due to electrification and industrialization, and stabilizes afterwards due to an increase in motorization and deindustrialization. Strikingly, along this period the ratio useful work/GDP varies by no more than $20 \%$ around its average and ends in 2009 at a value quite close to is 1856 value, around $1 \mathrm{MJ} / 2010 €$.
\end{abstract}

Keywords: energy; exergy; useful work; efficiency; energy intensity. 


\section{Introduction}

Dramatic changes occurred in energy use patterns over the recent centuries, with corresponding changes in the natural resources used to provide energy. In the $18^{\text {th }}$ century industrializing countries shifted from wood-fired rural societies to coal-fired industries and later from coal to oil. More recently electricity was introduced as a new energy vector, and its increasing pervasiveness is linked to the transition from industrial to service economies. An exponential increase in the quantities of energy used, as well as drastic changes in energy quality took place and were linked to enormous wealth accumulation, population growth and an impressive improvement in the standard of living. These changes in terms of energy quantity, quality and the way in which energy sources are used are commonly known as energy transitions (Fouquet, 2008; Grübler and Nakićenović, 1996; Henriques, 2011; Krausmann et al., 2009; Schandl et al., 2009; Smil, 1991; Steinberger and Krausmann, 2011; Stern, 2004; Stern and Cleveland, 2004; Warr et al., 2010).

Studies on energy transitions can be focused on changes over time (1) in the use of natural resources (primary energy) and energy vectors (final energy) or (2) in the energy uses (useful energy). A vast bibliography explores these issues, however most studies focus on primary energy or final energy (Apergis and Payne, 2010; Chontanawat et al., 2008; Kümmel et al., 1985; Miketa and Mulder, 2005; Mulder and Groot, 2007; Stern, 1993). These approaches are useful to analyse transitions in energy supplies (where the energy comes from), but they do not capture how energy is used productively within the economic system, and consequently neglect the structure and the motivation for energy demand.

Exergy is a thermodynamic measure of energy quality, measuring the availability to perform work of a certain amount of energy, given reference environmental conditions. Exergy is extensively presented in the literature as a good variable for economic and sustainability assessments of energy, as it accounts for the quality in use and conversion of energy vectors and materials. Several exergy analyses (primary, final, and useful) have been done for different countries, such as single year studies for the USA (Reistad, 1975), Sweden (Wall, 1987), Japan (Wall, 1990), Italy (Milia and Sciubba, 2006; Wall et al., 1994), China (Dai et al., 2014), Turkey (Seckin et al., 2013), United Kingdom (Gasparatos et al., 2009b), and the Netherlands (Ptasinski et al., 2006), and historical analyses of patterns of exergy consumption for China (Chen and Chen, 2007a, b, c; Chen and Chen, 2007d; Chen and Qi, 2007) and 
the United Kingdom (Gasparatos et al., 2009a, c). These works provide relevant economy-wide results, characterizing exergy flows, and exergy sources and consumers, but neither capture long-term trends and transitions nor explore the relations between exergy use and economic growth. We show here that useful work is a suitable energy measure to fulfil this task.

Useful work is the useful exergy of a given energy end use. It measures the result of an energy use rather than the amount of energy transferred to a final use. Formally, useful work can be defined as the minimum amount of work (or exergy) required to produce a given energy transfer. Useful work accounting implies an exergy analysis at the useful stage of energy flows (Figure 1), and measures the actual amount of exergy (and not energy) delivered to a final function, e.g. the mechanical work actually used by a car from its fuel, the exergy of the heat actually provided to a blast furnace, or the light emitted by an electric lamp. Useful work accounting at a country-level enables the assessment of the quality of the energy used in an economy, providing better insights on the relation between economic growth and energy use (Ayres, 2008; Ayres et al., 2003; Ayres and Warr, 2005; Stern, 2010; Warr and Ayres, 2006, 2010; Warr et al., 2010; Warr et al., 2008; Williams et al., 2008).
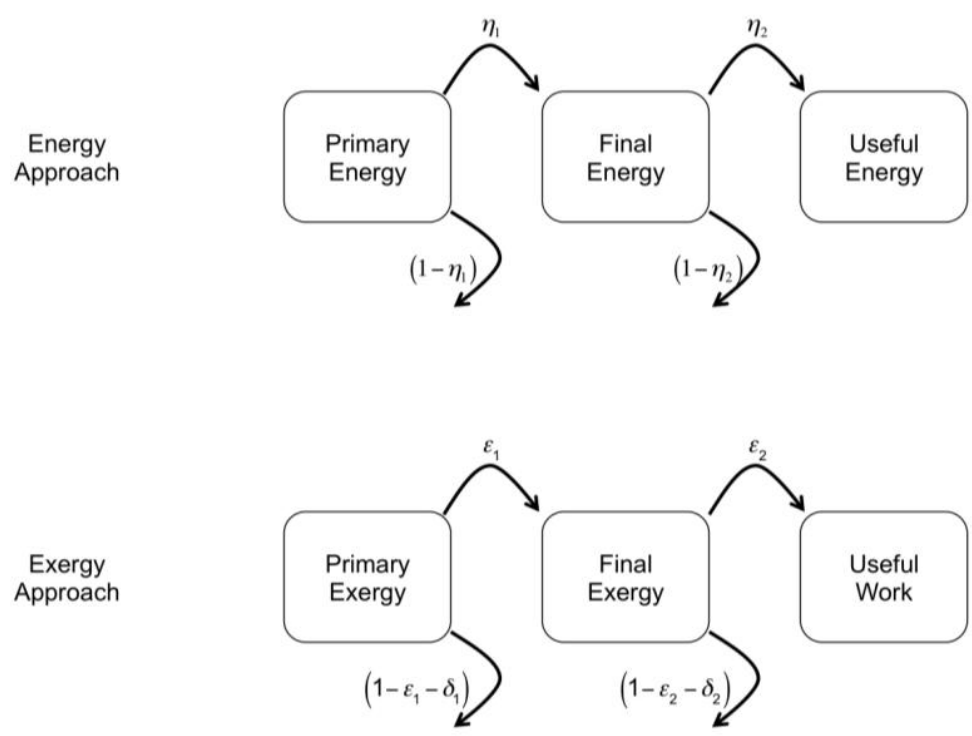

Figure 1. Primary-to-useful energy and exergy flows. Transformation and conversion energy and exergy efficiencies are represented as $\boldsymbol{\eta}_{\mathbf{1}}, \boldsymbol{\eta}_{\mathbf{2}}$ and $\boldsymbol{\varepsilon}_{\mathbf{1}}, \boldsymbol{\varepsilon}_{2}$, respectively. Exergy destruction during conversion and transformation is represented as $\boldsymbol{\delta}_{\mathbf{1}}$ and $\boldsymbol{\delta}_{2}$, respectively.

Comprehensive useful work analyses have been made for the USA, United Kingdom, Japan and Austria (Ayres, 2008; Ayres et al., 2003; Ayres and Warr, 2005; Warr et al., 2010; Warr et al., 2008), 
comprising the $20^{\text {th }}$ century transitions and economic transformations, but none covers the full transition from a rural society through an industrial economy to a service economy. Here, we accomplish the analysis of a full transition, accounting for useful work in Portugal for a 154-year period (1856 to 2009).

One of the two main energy transitions usually considered is associated to the so-called second industrial revolution, with the introduction of electricity and oil as significant energy carriers. These two energy carriers, given their typical end-uses, have radically different final-to-useful $2^{\text {nd }}$ law efficiencies, e.g., an electrical engine converts electricity to mechanical work at an efficiency greater than $70 \%$ and in some cases going up to more than $90 \%$ whilst a diesel or gasoline motor engine converts fuel to mechanical work at an efficiency in the range 10-13\%. However, different final uses for electricity can have very different efficiencies and so it is crucial to correctly account for these differences.

Previous useful work analyses (Ayres, 2008; Ayres et al., 2003; Ayres and Warr, 2005; Warr et al., 2010; Warr et al., 2008) considered an aggregate electricity final-to-useful efficiency equal to the average electricity final-to-useful efficiency of the USA, originally obtained in Ayres et al. (2005). Here we refine the useful work methodology considering separate final-to-useful efficiencies of the different electricity end-uses and sectors of the economy, since the sectoral structure of each country (other than USA) determines the useful work obtained from electricity.

The roadmap of this paper is as follows. We define useful work and describe the methodology in section 2. From historic energy records, we estimate final exergy figures and its breakdown in terms of energy vectors and useful work categories (section 3). In section 4, we estimate the final exergy-to-useful work conversion efficiencies for each category of use. We obtain and discuss the final exergy and useful work series for this country and period by types of use, as well as aggregate conversion efficiencies (section 5). Also, we compare the evolution of the useful work intensity in Portugal to intensity measures previously obtained for other countries (Warr et al., 2010). The differences of the Portuguese case, its meaning and consequences are discussed. We conclude by summarizing the main conclusions (section 6). 


\section{Methodology and data}

Useful work accounting comprises a four-step methodology for each year and energy vector (Ayres et al., 2003):

1. Conversion of existing final energy data to final exergy values (section 2.1);

2. Allocation of the final exergy consumption of each final use sector to useful work categories (sections 2.2 and 3);

3. Estimation of second-law efficiencies for each final-to-useful transformation (sections 2.3 and 4);

4. Calculation of an overall useful work value by summing the total values obtained for each useful work category.

This methodology was applied to Portuguese energy data from 1856 to 2009. Energy data from 1960 to 2009 was collected from International Energy Agency (IEA) Energy Statistics and Energy Balances (IEA, 2011a, b). Historical estimates prior to 1960 were assembled from Henriques (2011).

\subsection{Converting final energy to exergy data}

Exergy is formally defined as the theoretical maximum amount of obtainable work when a thermodynamic system is brought to a reference state of thermodynamic equilibrium. Therefore, calculating exergy values from energy values, depend on the ability that different forms of energy have to deliver work. In most energy calculations, energy is displayed in one of the following forms: fuel, electricity, mechanical work, heat or non-energy products. For each form, the exergy content is different (Table 1). Mechanical (both kinetic and potential) and electric energy flows can be, in theory, completely converted to work, thus they have an exergy factor ${ }^{1}$ of 1 , while in the case of heat, the exergy factor is smaller than 1 . Therefore, an electric energy flow can be completely converted to work and its exergy content equals its energy ${ }^{2}$ (Table 1 , row 2 ), while heat cannot be completely converted

\footnotetext{
${ }^{1}$ Exergy factor is commonly defined as the ratio of exergy to energy.

${ }^{2}$ In practice there are heat losses when converting for example kinetic energy to work, but they are unknown a priori, thus one decides to consider an efficiency of 1 which is the theoretical maximum given by the first law of thermodynamics, i.e. there is no
} 
to work. In this case the maximum work extractable from a sub-system connected to a thermal reservoir at $T_{0}$ is the work obtained by an ideal Carnot engine (Table 1, row 4).

Table 1. Exergy content of different energy flows. Adapted from Ford et al. (1975); Moran and Shapiro (2004); Sciubba and Wall (2007); Szargut et al. (1988).

$\boldsymbol{T}_{\mathbf{0}}$ is the environment temperature and $\boldsymbol{T}$ is the temperature of the reservoir from which heat is added.

\begin{tabular}{|c|c|c|}
\hline Energy flow $(E)$ & Exergy content $(B)$ & Observations \\
\hline Fuel & $B=-\Delta G=|\Delta H|-T_{0} \Delta S \approx|\Delta H|$ & The maximum work done by a fuel is the chemical \\
& work of its combustion. The term $T_{0} \Delta S$ is the heat \\
\hline Electricity & $B=E$ & rejected as a consequence of the entropy received. \\
\hline Work & $B=E\left(1-\frac{T_{0}}{T}\right)$ & Electricity can be completely converted to work. \\
\hline Heat & $B$ Available work is exergy by definition. \\
\hline
\end{tabular}

Obtaining useful work statistics for a region/country implies the calculation of exergy from available energy datasets. We take into account exergy inputs that go beyond conventional energy accounting statistics: food for humans, feed for working animals and non-conventional sources, such as wind and water streams for mechanical drive uses in boats, mills and wells. This accounting involved the following groups of energy vectors:

- Coal and coal products;

- $\quad$ Oil and oil products;

- Natural gas;

- $\quad$ Combustible renewables;

- $\quad$ Electricity and CHP heat ${ }^{3}$;

theoretical thermodynamic result that sets a maximum conversion efficiency in this case. Therefore, we consider electricity as 'pure work',

${ }^{3}$ Combining electricity and CHP heat in a single category may not be an adequate choice. However, IEA data assembles these two final energy uses in this group of energy vectors. Evidently, electricity and heat uses are handled differently in this paper, in terms of their distinct exergy contents and efficiencies. 
- $\quad$ Food and feed;

- Other non-conventional.

Different data sources were used to compile this dataset. Final energy use regarding coal and coal products, oil and oil products, natural gas, combustible renewables ${ }^{4}$, and electricity and CHP heat were obtained from the IEA energy balances databases from 1960 to 2009 (IEA, 2011a). For the remaining period, final energy regarding these groups was estimated based on the primary energy dataset of Henriques (2011). Final energy use in the form of coal was obtained from primary coal subtracting the amount of coal used for electricity generation (DGSE, 1929-1984), which was estimated considering a time varying thermal power plants average efficiency also estimated by Henriques (2011). This is a reasonable procedure, because electricity generation is the only transformation process for coal since the early $20^{\text {th }}$ century. For oil and oil products' final energy use, we used an analogous procedure, taking also into account crude oil used in refineries ${ }^{5}$ to produce oil products. Electricity figures prior to 1960 were estimated based on primary electricity values from Henriques (2011) plus electricity outputs from coal and oil (DGSE, 1929-1984; Henriques, 2011). CHP was not used before 1960.

Food for humans and feed for working animals have a quantitatively important role in the Portuguese economy, even though omitted in standard energy statistics. Food data prior to 1960 was obtained from Henriques (2011). From 1960 onwards, food intake data was obtained from the Food and Agriculture Organization of the United Nations database (FAO, 2011). Feed for working animals was estimated from the inventories of working animals in Henriques (2011).

Finally, energy data regarding other non-conventional vectors were obtained directly from Henriques (2011) for the entire timespan.

The consistency of the datasets used was verified for the transition or overlap years and differences of no more than 5\% were found (DGSE, 1929-1984; FAO, 2011; Henriques, 2011; IEA, 2011a).

\footnotetext{
${ }^{4}$ For combustible renewables, it was used the data from Henriques (2011) prior to 1990, and the IEA databases from 1990 onwards.

${ }^{5}$ The first refinery operating in Portugal was installed in Lisbon in 1940. Before this year, all oil products were directly imported and the only exit of imported oil products to transformation processes was for electricity generation.
} 
Exergy data was computed from final energy estimated figures based on different exergy factors for each group of energy vectors (Table 2).

Table 2. Exergy factor for energy vectors (Chen and Chen, 2006; Ertesvåg and Mielnik, 2000; Nakicenovic et al., 1996; Wall et al., 1994).

\begin{tabular}{lc} 
Energy carriers & Exergy factors \\
\hline Coal and coal products & 1.06 \\
Oil and oil products & 1.06 \\
Natural gas & 1.04 \\
Combustible renewables & 1.11 \\
Electricity and CHP heat & 1.00 \\
Food and feed & 1.00 \\
Other non-conventional & 1.00 \\
\hline
\end{tabular}

\subsection{Useful work categories}

Useful work was classified within 5 different categories of use: heat, mechanical drive, light, other electric uses and muscle work. Non-energy uses are not considered ${ }^{6}$.

Heat includes all final energy uses where heat is used in a given process or device. Because of the strong influence of temperature on second-law efficiencies, the heat category is often subdivided in at least three different subcategories for different temperature ranges of the hot reservoir. The first is high temperature heat for reservoirs warmer than $500^{\circ} \mathrm{C}$. These temperatures are used in some heat demanding industrial processes, mainly iron and steel industries, cement production, glass making and petroleum refining. A second group is medium temperature heat for reservoirs between $120^{\circ} \mathrm{C}$ and

\footnotetext{
${ }^{6}$ Non-energy uses include all exergy uses whose goal is not an energy-related exploitation of a resource. The main examples are oil products such as plastics or lubricants that comprise exergy as they are a product of an energy resource, but its use is not as an energy flow but capital stock. To assess the overall exergy flow in a country, material flow analysis would be needed in order to account for the total (chemical) exergy of materials used, including metal-ore derived materials. The exergy embedded in material flows is out of the scope of the current analysis, as our main goal is the assessment of the services provided by energy vectors only. However, a full scale exergy accounting from resources to end-uses that takes into account materials embedded exergy could enable the assessment of both energy and non-energy uses, and an assessment of different material efficiency options in the consumption of exergy resources.
} 
$500^{\circ} \mathrm{C}$ (with the majority of cases below $200^{\circ} \mathrm{C}$ ). This range of temperatures is widely used as process heat in the majority of industrial sectors. Finally, a low temperature heat class for temperatures below $120^{\circ} \mathrm{C}$ is defined for hot water, cooking and space heating uses (Ayres and Warr, 2010). This class of low temperature heat is further subdivided in several classes, because second-law efficiencies are much more sensitive to lower than higher temperatures. This enables a higher specification of second-law efficiencies for each different low temperature heat use. For all heating categories, different second-law efficiencies ${ }^{7}$ definitions are used depending on the type of energy source according to Table 3, eqs. (4) to (6), and taking into account the specific process temperatures.

\footnotetext{
${ }^{7}$ For simplicity, when referring to second-law efficiencies, we mean final-to-useful second-law efficiencies.
} 
Table 3. Second-law efficiencies ( $\boldsymbol{\epsilon})$ of some frequent end-use devices. Adapted from Ford et al. (1975).

Note: $T_{1}>T_{2}>T_{0}>T_{3}$. Definitions: $W_{\max }$ is the maximum amount of work that could be produced from the relevant energy input; $W_{\min }$ is the minimum amount of work required to produce the desired energy transfer; $B$ stands for exergy; $|\Delta H|$ is the heat of combustion; and $\eta$ and $\epsilon$ are the fist- and second-law efficiencies, respectively.

\begin{tabular}{|c|c|c|c|c|}
\hline End Use & Source & $\begin{array}{l}\text { Work } \\
W_{\text {in }}\end{array}$ & $\begin{array}{l}\text { Fuel } \\
\text { Heat of combustion }|\Delta H|\end{array}$ & $\begin{array}{c}\text { Exergy } B \\
\text { Heat } Q_{1} \text { from hot resevoir at } \\
T_{1}\end{array}$ \\
\hline & & $W_{\max }=W_{i n}$ & $W_{\max }=B$ & $W_{\max }=Q_{1}\left(1-\frac{T_{0}}{T_{1}}\right)$ \\
\hline $\begin{array}{l}\text { Work } \\
W_{\text {out }}\end{array}$ & $W_{\min }=W_{\text {out }}$ & $\epsilon=\eta=\frac{W_{o u t}}{W_{\text {in }}}$ & $\epsilon=\frac{W_{\text {out }}}{B} \approx \eta$ & $\epsilon=\frac{W_{\text {out }}}{Q_{1}\left(1-\frac{T_{0}}{T_{1}}\right)}=\frac{\eta}{1-\frac{T_{0}}{T_{1}}}$ \\
\hline $\begin{array}{c}\text { Heat } Q_{2} \\
\text { added to } \\
\text { warm } \\
\text { reservoir at } \\
T_{2}\end{array}$ & $\begin{array}{l}W_{\min }= \\
Q_{2}\left(1-\frac{T_{0}}{T_{2}}\right)\end{array}$ & $\epsilon=\frac{Q_{2}}{W_{\text {in }}}\left(1-\frac{T_{0}}{T_{2}}\right)=\eta\left(1-\frac{T_{0}}{T_{2}}\right)$ & $\epsilon=\frac{Q_{2}}{B}\left(1-\frac{T_{0}}{T_{2}}\right) \approx \eta\left(1-\frac{T_{0}}{T_{2}}\right)$ & $\epsilon=\frac{Q_{2}\left(1-\frac{T_{0}}{T_{2}}\right)}{Q_{1}\left(1-\frac{T_{0}}{T_{1}}\right)}=\eta \frac{1-\frac{T_{0}}{T_{2}}}{1-\frac{T_{0}}{T_{1}}}$ \\
\hline $\begin{array}{l}\text { Heat } Q_{3} \\
\text { extracted } \\
\text { from cool } \\
\text { reservoir at } \\
\qquad T_{3}\end{array}$ & $\begin{array}{l}W_{\min }= \\
Q_{3}\left(\frac{T_{0}}{T_{3}}-1\right)\end{array}$ & $\epsilon=\frac{Q_{3}}{W_{\text {in }}}\left(\frac{T_{0}}{T_{3}}-1\right)=\eta\left(\frac{T_{0}}{T_{3}}-1\right)$ & $\epsilon=\frac{Q_{3}}{B}\left(\frac{T_{0}}{T_{3}}-1\right) \approx \eta\left(\frac{T_{0}}{T_{3}}-1\right)$ & $\epsilon=\frac{Q_{3}\left(\frac{T_{0}}{T_{3}}-1\right)}{Q_{1}\left(1-\frac{T_{0}}{T_{1}}\right)}=\eta \frac{\frac{T_{0}}{T_{3}}-1}{1-\frac{T_{0}}{T_{1}}}$ \\
\hline
\end{tabular}

Mechanical drive includes all mechanical work end uses. It comprises all types of conversion to physical work, regardless the energy source. However, since different energy sources have different second-law efficiencies, source-specific subcategories of mechanical drive are considered, rather than a rough estimation of an aggregate efficiency for this category (eq. (2)). The most common uses in this category are internal combustion engines (depending on the source, natural gas, gasoline, diesel and aviation engines are distinguished), animal-drawn vehicles, and electric engines. The necessary disaggregation of data by final use sector and energy vector allows for the subdivision of this category in two main types of mechanical drive: transport (both freight and passenger) and stationary mechanical drive. 
Light includes the total lighting end uses whatever the energy source. Nowadays lighting comes almost all from electricity, although in the beginning of the $20^{\text {th }}$ century most lighting was produced from oil products, fat or "town gas" made from coal. Light efficiency calculations differ from other categories in their methodology. Light efficiency does not measure the share of exergy used that is transformed in a useful work output, because it is measured in lumens per Watt ${ }^{8}$. The use of a different methodology in this case may raise a question of consistency. However this lighting efficiency methodology is widely used in lighting literature and efficiency studies (Ayres et al., 2005; Fouquet and Pearson, 2006; Nordhaus, 1998).

Other electric uses include all electricity final uses that do not provide heat, mechanical drive or light. The main examples are electronic equipment and electrochemical uses of electricity. Their estimation was based on previous historical studies (Ayres et al., 2005; Rosen and Bulucea, 2009).

The muscle work category comprises useful work from feed and food energy uses, i.e. the useful share of human intake of food exergy. It takes into account the food consumption of the country. Efficiency calculations in this category consider the human and animal efficiency of converting exergy from food or feed to muscle work. This muscle work category aims to quantify the mechanical work produced by humans and animals, without measuring the exergy embodied in human labour as in the Extended Exergy Accounting method suggested by Rocco et al. (2014).

\subsection{Measuring efficiencies}

In thermodynamics one often considers two different efficiency definitions: energy efficiency, or first-law efficiency, and exergy efficiency, or second-law efficiency (Cullen and Allwood, 2010; Ford et al., 1975; Hammond and Stapleton, 2001).

Energy efficiency expresses the fraction of energy of desired kind that is transferred in a process. It is defined as (Ford et al., 1975)

\footnotetext{
${ }^{8}$ Lumen is a unit of luminous flux, which is a measure of the share of visible light emitted by a luminous source. It achieves a maximum for a source emitting green light with a wavelength of $555 \mathrm{~nm}$ - the colour to which the human eye is most sensitive. Lumen per watt is therefore a measure of the luminous efficacy of a given source, for which an ideal $555 \mathrm{~nm}$ source has 683 $\ln / \mathrm{W}$, or $100 \%$ efficiency.
} 


$$
\eta=\frac{\text { desired energy transfer }}{\text { relevant energy input }}
$$

For example, when assessing a power cycle the first-law efficiency is the quotient of the net work done by the cycle and the heat input to the cycle. As a consequence of the $1^{\text {st }}$ and the $2^{\text {nd }}$ laws of thermodynamics, we get $0 \leq \eta<1$ in this case. However, energy efficiency does not behave this way for all energy uses and devices. Heat pumps exhibit first-law efficiencies greater than 1, because the relevant energy input does not include the heat input from the environment (the cold reservoir).

Since the domain of $\eta$ is any positive real number, this example demonstrates that the first-law efficiency does not provide a comparable figure of merit across energy uses (Ford et al., 1975).

The second-law efficiency is defined as the ratio of end use/source in exergy terms (Cullen and Allwood, 2010; Moran and Shapiro, 2004):

$$
\epsilon=\frac{\text { desired exergy output }}{\text { relevant exergy input }} \text {. }
$$

This second-law efficiency is widely accepted and used as a figure of merit for energy use. It measures for each process the distance from the theoretical ideal process, as it compares the actual amount of work output with the theoretical maximum.

As a consequence of the second law of thermodynamics, exergy efficiency is bounded by $0 \leq \epsilon \leq 1$, and therefore the $2^{\text {nd }}$ law efficiency expresses a figure of the quality and closeness to an ideal process for a given energy use.

To obtain $2^{\text {nd }}$ law efficiency values in this work we will use the following definition, obtained directly from eq. (11) applying the definition of exergy:

$$
\begin{aligned}
& \text { minimum amount of work } \\
& \epsilon=\frac{\text { required to produce the desired energy output }}{\text { maximum amount of work }} \text { that could be produced from the relevant energy input }
\end{aligned}
$$

This definition is useful in the context of this paper because we want to measure and study the performance of energy uses throughout a country or an economy. Table 3 presents the second-law 
efficiency for several sources and end-uses of energy. The use of eq. (12) allows for a clear intuition on Table 3: each row (end use) has the same expression for the minimum amount of work and each column (source) has the same expression for the maximum. For example, eq. (7) is the ratio $\frac{W_{\min }}{W_{\max }}$ with $W_{\text {min }}=Q_{3}\left(\frac{T_{0}}{T_{3}}-1\right)$, because in a Carnot refrigeration cycle (the ideal situation) $Q_{3}\left(\frac{T_{0}}{T_{3}}-1\right)$ is the amount of work required to extract $Q_{3}$ from a cold reservoir at $T_{3}$. Also $W_{\max }=W_{\text {in }}$ because the source is work itself.

\subsection{Useful work for each year}

Useful work values for each year $(U)$ can be obtained after the estimation of second law final-to-useful efficiencies, as

$$
U=\sum_{i} \epsilon_{i} B_{i}
$$

where $B_{i}$ stands for the final exergy of the useful work category $i$ and $\epsilon_{i}$ is the second-law final-to-useful efficiency for the useful work category $i$.

\section{Allocation of final exergy to useful work categories}

A straightforward allocation of final energy to useful work categories can be made regarding food and feed - for muscle work - and the other non-conventional vectors - for mechanical drive. However, the allocation procedure becomes more complex regarding the remaining energy vectors.

Regarding coal and oil products, natural gas and combustible renewables, the allocation of final energy uses to useful work categories was made for the period 1960 to 2009 from IEA energy balances, based on the sectoral disaggregation provided by this database (Appendix A). However, for former years the allocation process is less intuitive. This allocation was based on existing records of national and international official entities for trade and customs and previous works on the history of energy use in Portugal (Appendix B). Regarding electricity, the allocation was based in detailed information that characterizes the electricity end-uses. A brief description of this allocation and of the idiosyncrasies of the use of each energy vector in Portugal is presented herein for each energy vector. 


\subsection{Coal}

Coal started to be used in Portugal by the end of the $18^{\text {th }}$ century when the first Portuguese coal mines started to be explored. First coal replaced firewood and served thermal uses in households, providing low temperature heat and space heating. Later, it was introduced in industries for the same uses (Henriques, 2006, 2011). The use of coal for mechanical drive was made possible by the huge railway investments in the late $19^{\text {th }}$ century. Another noteworthy coal consumer are boats, but their consumption figures are very difficult to track (Henriques, 2011). Therefore we assumed the growth rate in the length of Portuguese railways as a proxy for the use of coal for mechanical drive ${ }^{9}$.

During the First World War coal consumption dramatically fell due to European instability and disturbance in coal imports. Portuguese domestic coal production was small and of low quality, which caused a temporary substitution of firewood for coal in thermal uses. After World War I some instability in coal imports remained and the use of coal declined. With the industrial promotion plans of the mid-1950's, a decreasing coal use became confined to some of the industrial medium and high temperature heat uses.

Since 1985, when the Sines thermoelectric power station started its activity, almost all uses of coal have been primarily assigned to electricity generation instead of heat. Also since 1985, coal consumption in the cement production industry has dominated coal direct final uses. Mechanical drive from coal took place mainly in steam locomotives that were replaced by the 1970's.

\subsection{Oil}

In Portugal all crude oil has to be imported. The country started in 1861 importing oil products such as kerosene and later butane and oil lubricants that were used in private and public lighting. The imports of gasoline, diesel and fuel-oil started in the first decades of the $20^{\text {th }}$ century. These combustibles were used for the first motor vehicles, but also for electricity and heat generation (DGSE, 1929-1984; Henriques, 2011; INE, 1875-2009).

\footnotetext{
${ }^{9}$ Rail traffic, rather than the length of railways, has a direct relation with exergy consumption. The lack of data on passenger-kilometres or tonnes-kilometres over such a long timeframe led us to assume traffic growth rate proportional to the length of railways' growth rate. However, since energy use in trains is extremely modest (less than $1 \%$ of the total final exergy consumption) for the overall results assessed in this paper, this proxy for rail energy use is considered to be satisfactory.
} 
Since 1941, Portuguese National Statistics started the assessment of energy uses in the industrial sector. Based on these figures, one can estimate the shares of mechanical drive and thermal uses from oil products (INE, 1941-1960).

During the last decades heating oil uses are shrinking, the use of oil to generate electricity has almost vanished and nearly $70 \%$ of final direct use of oil products occurs in the transport sector.

\subsection{Natural gas}

Natural gas was introduced in Portugal in 1997 after the construction of a gas pipeline that enabled natural gas imports from Algeria. The introduction of natural gas substitutes some energy services provided by coal, combustible renewables and mainly by oil products. Its most important uses occur in the heavy industry sector, mainly for medium and high temperature heat. Domestic sector shares of use for space and water heating and cooking almost stabilized since 2000. Electricity generation from natural gas is also a very important secondary use.

\subsection{Combustible renewables}

Combustible renewables were used mainly for low temperature heat and space heating uses. Henriques (2011) provides data on firewood energy final uses by households, industries and transport sector. It is reasonable to think that all domestic use of firewood is for cooking, space and water heating, falling within the category of low temperature heat uses. Also, firewood uses by the transport sector provide mechanical drive as a substitute for coal in years of coal scarcity.

Industrial uses of firewood are more difficult to assess. Different uses can be made, however it is reasonable to think that all of them are thermal energy uses. Different industrial activities, even in the $19^{\text {th }}$ century, required high or medium temperatures in their processes, e.g. foundries and ceramics and glass processing. Therefore we assumed a $50 \%$ split for medium temperature uses and $50 \%$ for low temperature heat uses of firewood in industry.

More recently other combustible renewables' products started being used, such as biofuels for mechanical drive. These uses occur significantly only after 1990, years for which we have detailed data available in the IEA energy balances (IEA, 2011a). 


\subsection{Electricity}

Since 1960 the IEA energy balances provide data on electricity consumption for each sector of the economy, although no detail on the electricity end-uses is known. For the pre-1960 period the lack of information is even more striking, since there is no available data on detailed sectoral electricity uses. To take advantage from existing detail for each period (before and after 1960) two methodologies were followed to estimate the shares of electricity uses by each useful work category.

Since 1960 it is possible to distinguish between industrial and non-industrial (domestic + services) electricity uses. Therefore we consider these two groups of electricity consumers in this period, for which we estimate shares of electricity uses by each useful work category. Portugal lacks consistent statistics on electricity uses. For the domestic sector INE only provides data on comfort indicators of households as well as on electricity uses and electric equipment owned by families since 1987 (DGGE, 2004; INE, 1987-1997, 2010). For the industrial sector in 1960, electricity uses are provided by Industrial Statistics (INE, 1941-1960). These datasets combined with information from the Energy Information Administration (EIA, 2006) for US industries provide an insight on the shares of electricity uses across sectors in Portugal since 1960.

For the period before 1960, to overcome the absence of convenient data, we used available information for Portugal of the shares of electricity uses by useful work category, and extrapolated the evolution of these shares for the entire time span, using the estimations on the evolution of the shares of different electricity uses in the USA (Ayres et al., 2005). Convenient adaptations were made in order to match the electricity end-uses in Ayres et al. (2005) and the useful work categories defined in section 2.2. Estimated shares of electricity end-use for each year are presented in the supplementary data file attached to this paper. 


\subsection{Other non-conventional}

Exergy inputs from non-conventional energy vectors comprise wind kinetic energy flows for sailing ships and fishery boats, as well as wind and water streams for cereal mills and industrial mills. These values are obtained from Henriques (2011) and accounted as pure mechanical drive uses.

\section{Second law final-to-useful efficiencies}

Useful work values can only be obtained after the estimation of second law final-to-useful efficiencies. In section 3, final exergy figures were obtained and allocated to useful work categories. This classification helps to identify specific patterns of energy use and consequently different aggregated final-to-useful efficiencies for each useful work category.

\subsection{Heat}

Heating final-to-useful efficiencies are obtained from eq. (4), (5) or (6), whenever heat is provided from electricity, a fuel combustion process, or a CHP facility, respectively. In any case, heat efficiencies depend on the first-law efficiency $(\eta)$, the environment reference temperature $\left(T_{0}\right)$ and the temperature at which heat delivery occurs $\left(T_{2}\right)$. Heating uses from CHP heat depend also on the temperature of the steam provided $\left(T_{1}\right)$.

Estimating heating final-to-useful efficiencies implies assessing the evolution of first-law efficiencies $(\eta)$ that capture the state of the art of heat end use devices. Technological changes in heat exchangers, boilers, furnaces, and radiators imply changes in first-law efficiencies of these devices. Heat exergy uses occur mainly in industry as process heat. Technological change in industry heat uses is not very well documented in the literature, except for ammonia and polyethylene industries, sectors where process heat plays a crucial role (Joyce, 1991; Smil, 2001). These studies provide data on energy productivity of ammonia and polyethylene industries that are adequate representatives for heat uses ${ }^{10}$. We can therefore estimate aggregate first- and second-law efficiencies for most of the $20^{\text {th }}$ century (Figure 2).

\footnotetext{
${ }^{10}$ Polyethylene and ammonia industries comprise the most relevant chemical industries in Portugal since 1960.
} 


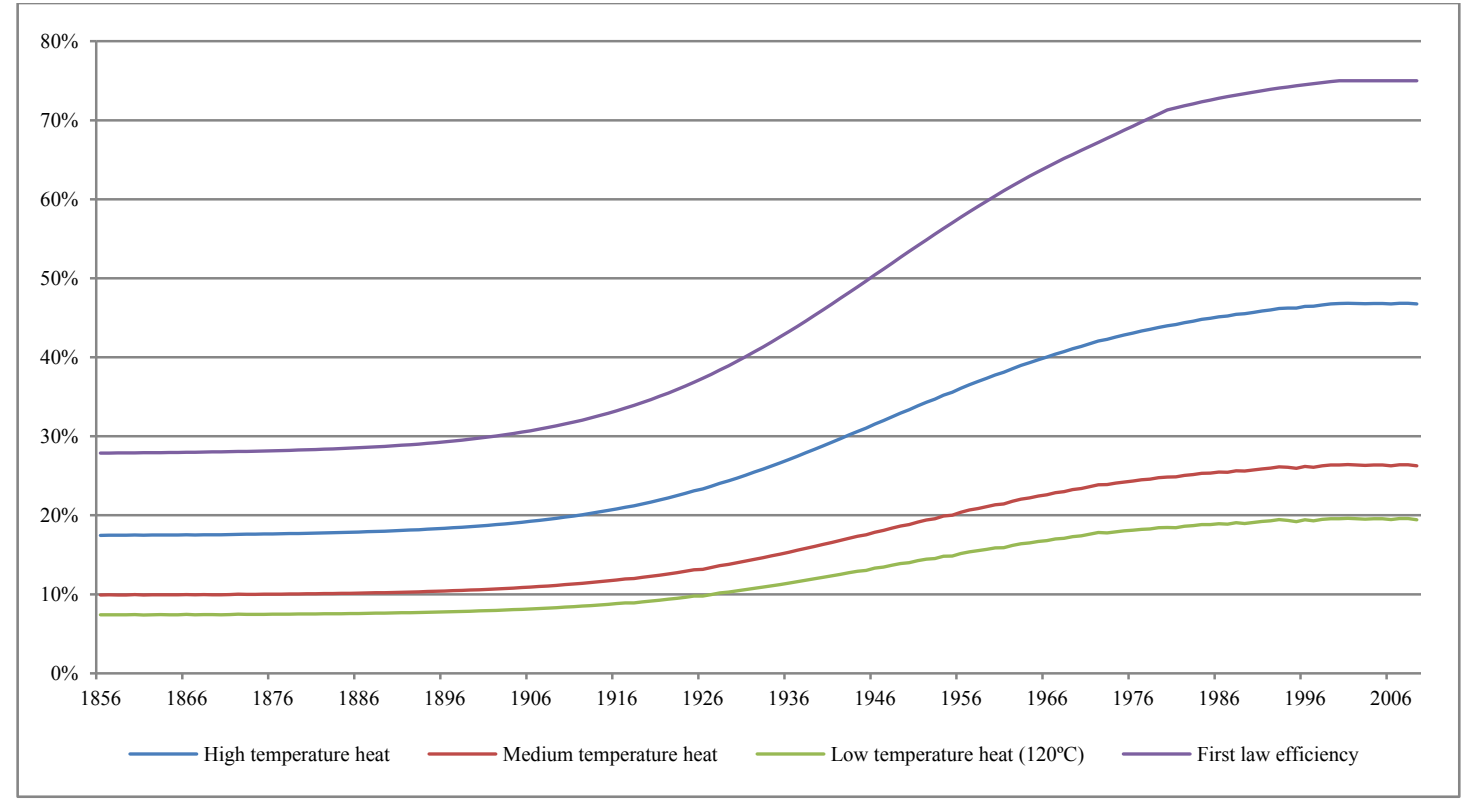

Figure 2. Second-law efficiencies of heat production from 1856 to 2009.

We have distinguished two different environment temperatures $\left(T_{0}\right)$ for each year to compute the heating second-law efficiencies: (i) the average temperature for the winter months in Lisbon ${ }^{11}$ for space heating uses; (ii) the yearly average air temperature for Lisbon for the remaining heat uses (IGIL, 1856-2007).

The temperature at which heat transfer occurs $\left(T_{2}\right)$ is chosen differently for each heating use category: high, medium or low temperature heat. As second-law efficiencies are much more sensitive to lower than higher temperatures, we subdivided low temperature heat in several subcategories, considering $T_{2}$ values from $23^{\circ} \mathrm{C}$ for space heating to $120^{\circ} \mathrm{C}$ for some industrial uses.

\footnotetext{
${ }^{11}$ Lisbon is located near Portugal centroid's latitude and is the biggest city, comprising a significant share of Portuguese industries. Also, thermal amplitudes within the Portuguese territory are not that significant. Therefore, it is reasonable to consider Lisbon temperatures as reference temperatures.
} 


\subsection{Mechanical drive}

Gasoline engines (those that perform Otto thermodynamic cycles) have a second-law efficiency given by (Ford et al., 1975; Heywood, 1988; Ross, 1997):

$$
\epsilon \approx \eta_{\text {theoretical maximum }} \prod_{i=1}^{6} \alpha_{i},
$$

where $0 \leq \alpha_{i} \leq 1, \forall i$ are coefficients that stand for the bias from real to ideal use settings and

$\eta_{\text {theoretical maximum }}$ depends on the compression ratio and the specific heat ratio $\left(\gamma=\frac{C_{P}}{C_{v}} \approx 1.4\right)$ :

$$
\eta_{\text {theoretical maximum }}=1-\left(\frac{1}{r}\right)^{\gamma-1}
$$

Table 4 shows the values for each coefficient $\alpha_{i}$ and Figure 3 shows the evolution for compression ratios.

\begin{tabular}{|c|c|c|c|}
\hline $\begin{array}{c}\text { Coefficient } \\
i \\
\end{array}$ & Meaning & $\begin{array}{l}\text { Approximate } \\
\text { value }\end{array}$ & Notes \\
\hline 1 & Reduction due to stoichiometry deviations. & 0.75 & $\begin{array}{l}\text { Deviations from stoichiometric conditions } \\
\text { occur just momentarily. }\end{array}$ \\
\hline 2 & Combustion and cylinder wall's losses. & 0.75 & \\
\hline 3 & Friction losses. & $0.75-0.90$ & $\begin{array}{l}\text { Friction losses have decreased during the } \\
\text { 20th century. We assumed an evolution from } \\
0.75 \text { to } 0.90 \text { between } 1900 \text { and } 2000 \text {. }\end{array}$ \\
\hline 4 & Partial load. & $0.40-0.50$ & $\begin{array}{l}\text { In average terms, vehicles partial load is very } \\
\text { low. Rare situations occur where full power } \\
\text { is used, except in heavy transport vehicles } \\
\text { that work close to the maximum. This } \\
\text { coefficient has been evolving during the 20th } \\
\text { century. By the beginning of the century } \\
\text { vehicle worked closer to full power. We } \\
\text { assumed an evolution from } 0.50 \text { to } 0.40 \\
\text { between } 1900 \text { and } 2000 \text {. }\end{array}$ \\
\hline 5 & Accessories losses (includes air conditioning). & 0.90 & \\
\hline 6 & Transmission losses. & $\begin{array}{l}0.75 \text { (autom.); } \\
0.90 \text { (manual) }\end{array}$ & $\begin{array}{l}\text { In Portugal and generally in Europe the vast } \\
\text { majority of vehicles have had manual } \\
\text { transmission. }\end{array}$ \\
\hline
\end{tabular}

Table 4. Considered $\alpha_{\mathrm{i}}$ coefficients. Based on Ford et al. (1975); Heywood (1988); Ross (1997). 


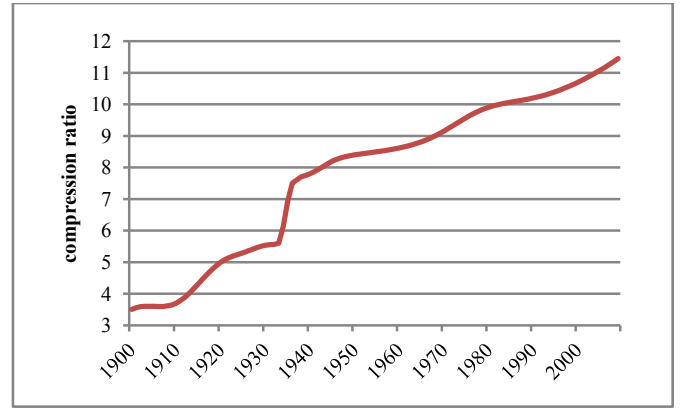

Figure 3. Compression ratio of standard gasoline engines from 1856 to 2009 .

Regarding Diesel vehicles, it is reasonable to assume that their second-law efficiency is $25 \%$ higher than gasoline vehicles, because a well designed Diesel engine exhibits a greater compression ratio and a better fuel-burning efficiency (Ford et al., 1975).

Mechanical drive uses also comprise other equipment such as steam locomotives, Diesel-electric locomotives, aviation engines, boat engines and electric motors. For these five different mechanical drive equipment, second-law efficiencies may be estimated based on previous studies. Since most of this equipment is imported, it is reasonable to think that it follows the efficiency evolution paths of other countries, namely central European countries and the USA (Ayres et al., 2003).

Figure 4 summarizes estimated second-law efficiencies for mechanical drive uses in Portugal. 


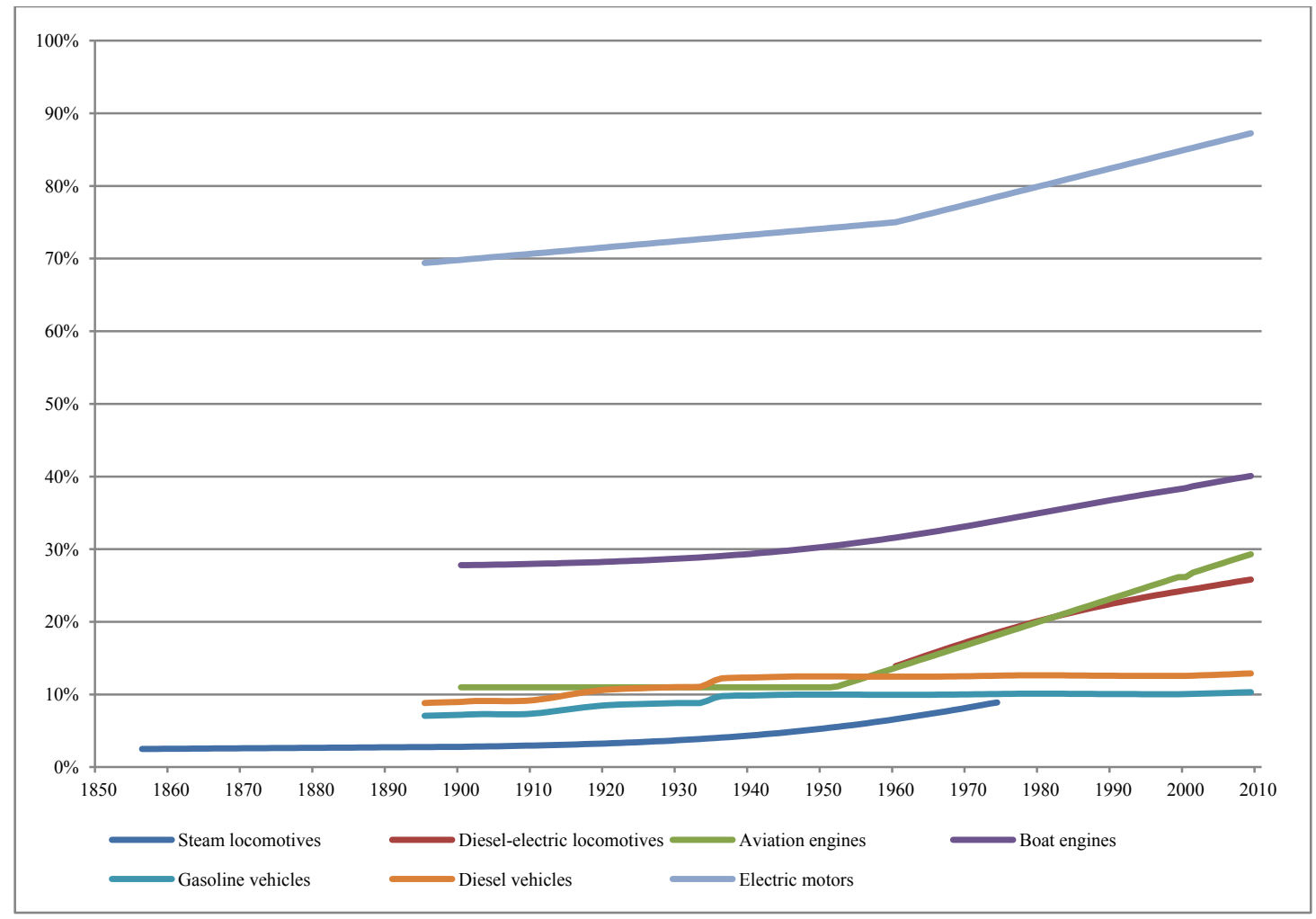

Figure 4. Mechanical drive equipment second-law efficiency from 1856 to 2009.

\subsection{Light}

Light end use efficiencies are well documented in the literature (Ayres et al., 2005; Fouquet and Pearson, 2006; Nordhaus, 1998). Lighting available technologies in Portugal did not differ in time significantly from other developed countries. It seems reasonable to apply US estimated efficiencies estimated by Ayres et al. (2005) to the Portuguese case.

\subsection{Other electric uses}

Ayres et al. (2005) subdivide other electric uses in two classes: (i) use in communication, electronic and electric devices; (ii) electrochemical uses. Using US second-law efficiencies from Ayres et al. (2005) and knowing the share of these two types of electricity (section 3.5) use we estimated secondlaw efficiencies for this useful work category. Other electric uses only gains relevance since the 1950's in Portugal, as a consequence of the huge industrial development that drove a significant increase in electricity uses. In this period the pattern of electricity use changed in Portugal, shifting from lighting uses to electrochemical and mechanical driving uses, mainly in industries. Since the 1970's the 
pervasive use of electric equipment, namely radios, TV sets, and more recently appliances, personal computers, and electronic devices, changed the electricity uses in households (Table 5). Such electronic devices comprise a significant diversity of end-uses and include heating, ventilation and air conditioning (HVAC), refrigeration and household appliances. Thus, this group exhibits an average second-law efficiency lower than electrochemical uses, causing an overall decrease in other electric uses' efficiency since the 1970's in Portugal.

Table 5. Dissemination of electric equipment in Portuguese homes in percentage (INE, 1970, 1976, 1983, 1987-1997, 1992, 1997, 2002, 2008, 2010).

\begin{tabular}{lrrrrrr}
\hline$\%$ & $\mathbf{1 9 6 0}$ & $\mathbf{1 9 7 0}$ & $\mathbf{1 9 8 0}$ & $\mathbf{1 9 9 0}$ & $\mathbf{2 0 0 0}$ & $\mathbf{2 0 0 5}$ \\
\hline Fridge & 75.6 & 81.1 & 86.8 & 91.9 & 97.1 & 99.0 \\
Electric heater & 18.8 & 27.1 & 35.1 & 40.8 & 52.0 & 53.3 \\
TV & 71.3 & 78.1 & 85.1 & 91.3 & 97.9 & 98.9 \\
Computer & 0.0 & 0.0 & 0.0 & 5.0 & 22.0 & 43.9 \\
\hline
\end{tabular}

Figure 5 shows estimated second-law efficiencies of light and other electric uses in Portugal.

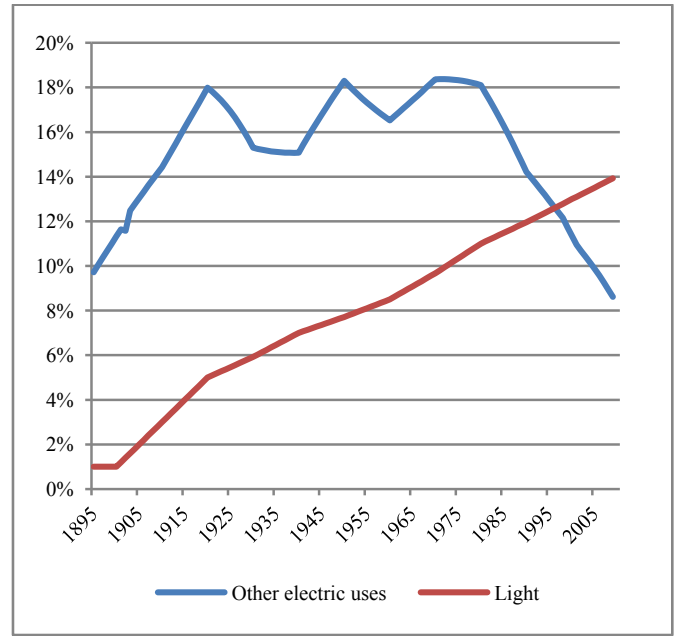

Figure 5. Light and other electric uses second-law efficiencies in Portugal from 1895 to 2009.

\subsection{Muscle work}

Muscle work is the sum of useful work provided by working animals and humans.

Used datasets provide data on food intake per capita as metabolizable energy (FAO, 2011; Henriques, 2011), which is the amount of energy in the consumed food that could be used by the organism. 
However, final exergy calculated must refer to food supply gross exergy data. These figures are obtained multiplying metabolizable data by a gross/metabolizable ratio which is estimated to be 1.23 for Western European countries, according to Wirsenius (2000).

However not all supplied food is eaten and a useful work calculation must take this into account. The supplied/eaten ratio has evolved from $95 \%$ in the second-half of the $19^{\text {th }}$ century to only $63 \%$ nowadays (Wirsenius, 2000).

Feed intake by working animals was provided by the statistics of Henriques (2011). Similarly to muscle work from food calculations, a gross/metabolizable ratio was estimated to be 1.54 and a supplied/eaten ratio of $64 \%$ was considered (Wirsenius, 2000).

Muscle work figures are obtained considering a food/feed-to-useful work efficiency of $13 \%$ for humans and working animals (Smil, 1994).

\section{Results and discussion}

Overall, we see that Portuguese final exergy consumption dramatically increased from nearly $100 \mathrm{PJ}$ in 1856 to 903 PJ in 2009, accompanying most developed countries (Figure 6). Final exergy and useful work results for each year are presented in the supplementary data file attached to this paper. 


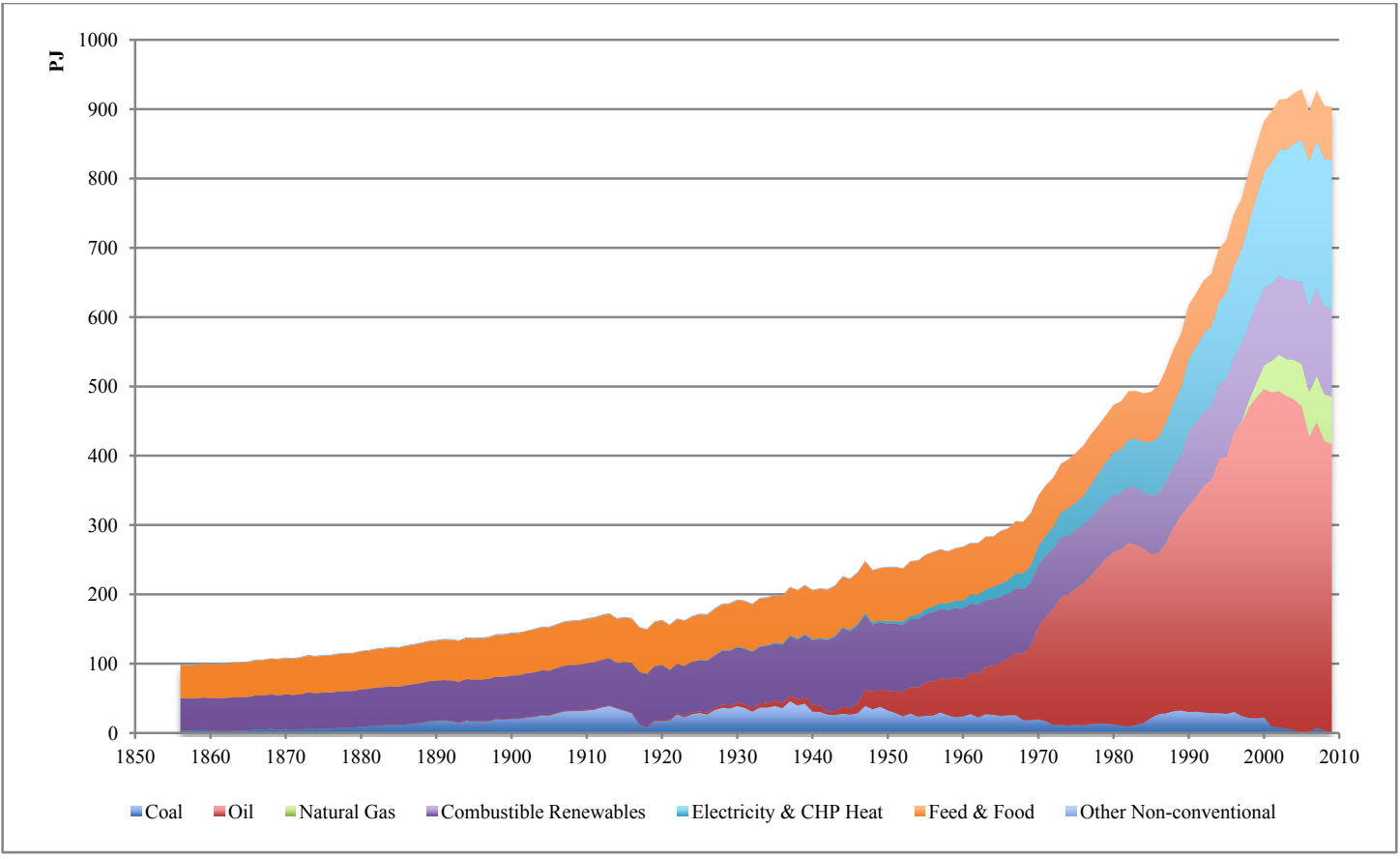

Figure 6. Portuguese final exergy inputs by vector.

The transition from feed, food and biomass to fossil fuels is visible during the analysed period. In 1856, biomass (including food and feed) accounted for nearly $95 \%$ of the total final exergy consumption in Portugal. In that year the first railway in Portugal between Lisbon and Carregado (a small town about $30 \mathrm{~km}$ north of Lisbon) was inaugurated. The first industrialization era had started in Portugal and fossil fuels started to gain relevance in the energy panorama. Thereafter the share of food and feed in societal exergy inputs dramatically decreased with the massive use of high-density energy vectors. Food and feed products evolved from quantitatively essential to irrelevant in the Portuguese energetic context.

Figure 6 shows that in this 154-year evolution there was a change in the final exergy mix input to the economy. Coal was the first class of fossil fuels introduced in Portugal. It gained relevance in the final exergy mix achieving nearly $20 \%$ by 1913 . However, a huge retraction of coal imports from European countries during the First World War ended the growing share of coal. In the post-WWI decades oil products started being used for mechanical drive and heating. Also since the mid-1940-decade electricity started gaining relevance. In quantitative terms the absolute figures of final exergy consumption rose significantly from the 1960-decade onwards as a consequence of vast industrialization programs known as the second industrialization era in Portugal. In the end of the $20^{\text {th }}$ 
century the energy transition from biomass products to fossil fuels and electricity has stabilized with an overall change from $95 \%$ to $20 \%$ of the share of biomass in total exergy inputs.

Portuguese useful work also increased substantially, from 6.6 PJ in 1856 to more than 175 PJ in 2009 (Figure 7). It is worth mentioning a more than 26-fold increase in useful work, a 9-fold increase in final exergy and an almost 3-fold increase in population over this timespan, showing different behaviours of these quantities due to efficiency improvements and transformations in intensities.

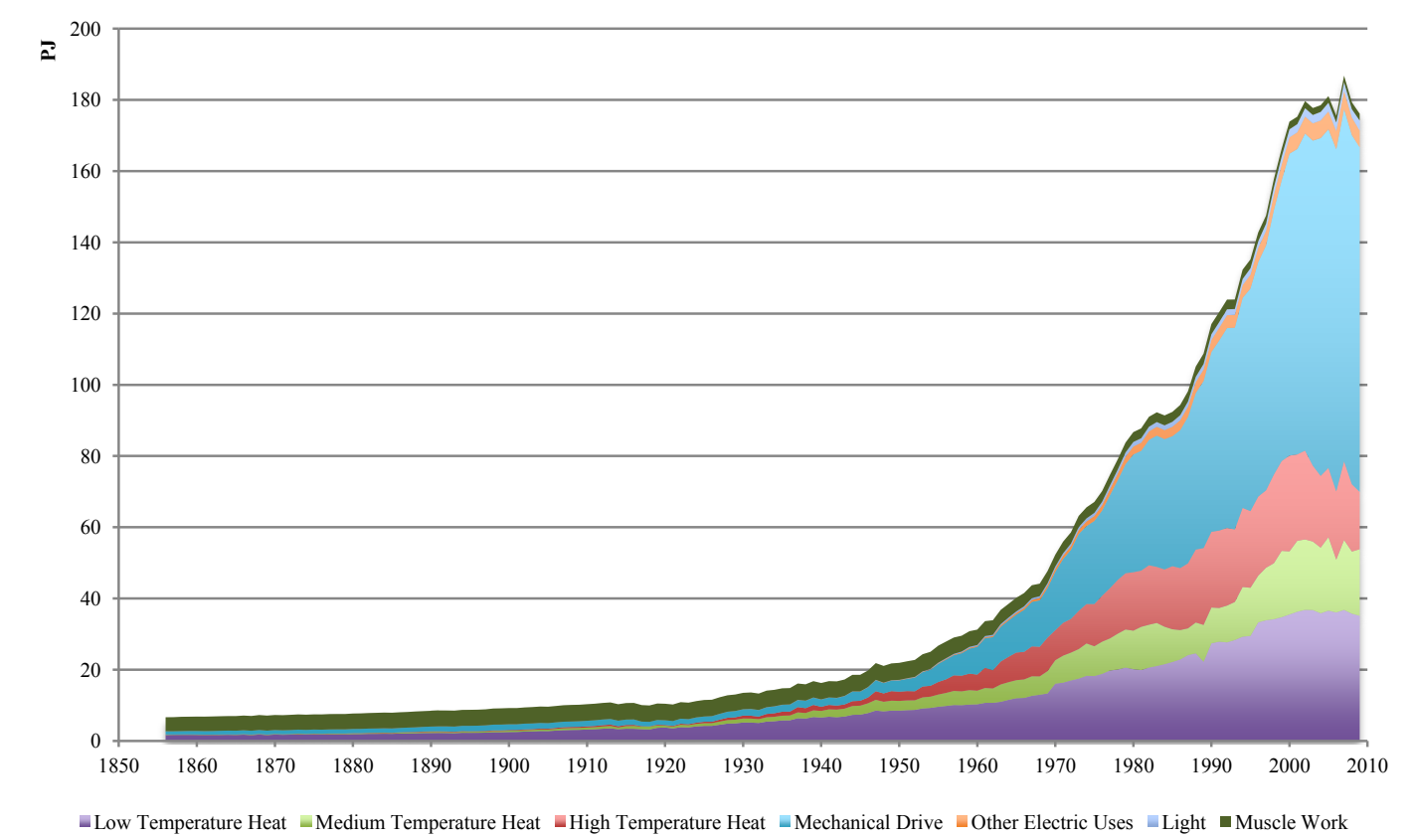

Figure 7. Portuguese useful work by category.

Over this timespan the structure of useful work categories changed in Portugal (Figure 8). The economy evolved to a higher dependency on mechanical drive services than in the past. Also, as referred, other electric uses and higher temperature heat uses gained importance. These changes happened as a consequence of the industrialization of the country and mobility needs that led to increases in transport sector energy uses. 


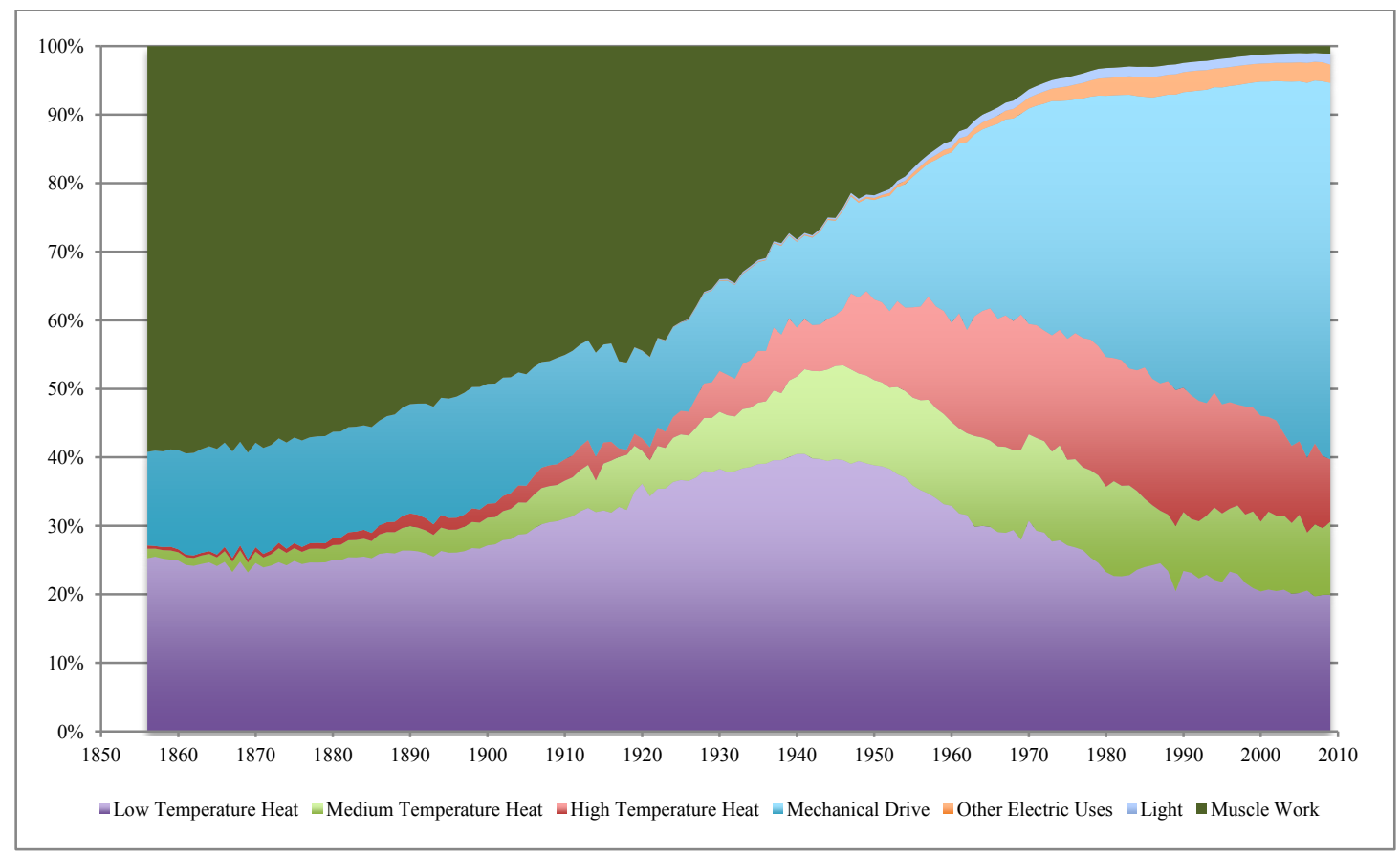

Figure 8. Useful work by category in percentage.

Relevant increases in the final-to-useful efficiency are visible, starting in the beginning of the $20^{\text {th }}$ century but in a more pronounced way since World War II (Figure 9). This shows technological progress at the energy use level, but is also a consequence of changes in the type of energy uses and energy vectors to a more efficient setup. Technological changes implied more efficient devices and enabled more efficient and valuable uses of energy. We can identify four different periods of efficiency improvements:

- Until 1920 - There are not significant changes. During this period exergy inputs are used for muscle work and low temperature heat, resulting in an aggregate efficiency between $6 \%$ and $7 \%$. Until 1920 there was a slight substitution from fuelwood to coal, keeping the exergy uses unchanged, and therefore with no significant impact on efficiencies.

- From 1920 to 1950 - There is a slight improvement in aggregate efficiency, mainly motivated by low, medium and high temperature heat uses and their efficiencies, as a consequence of a phase of primordial industrialization in Portugal.

- From 1950 to 1980 - This was the period with fastest efficiency improvements, mainly motivated by the electrification process that occurred firstly in industries, providing electric stationary work. This led to the pervasive use of electric mechanical drive (second-law efficiencies of about $70-80 \%$ ). Another factor was the increasing high temperature heat uses 
(second-law efficiencies of about $34-44 \%$ ), caused by the second industrialization era in Portugal.

- From 1980 onwards -The aggregate efficiency stabilized between $18 \%$ and $20 \%$ after 1980 , due to a significant increase in automobile uses that have offset the continuing but slowing down electrification process.

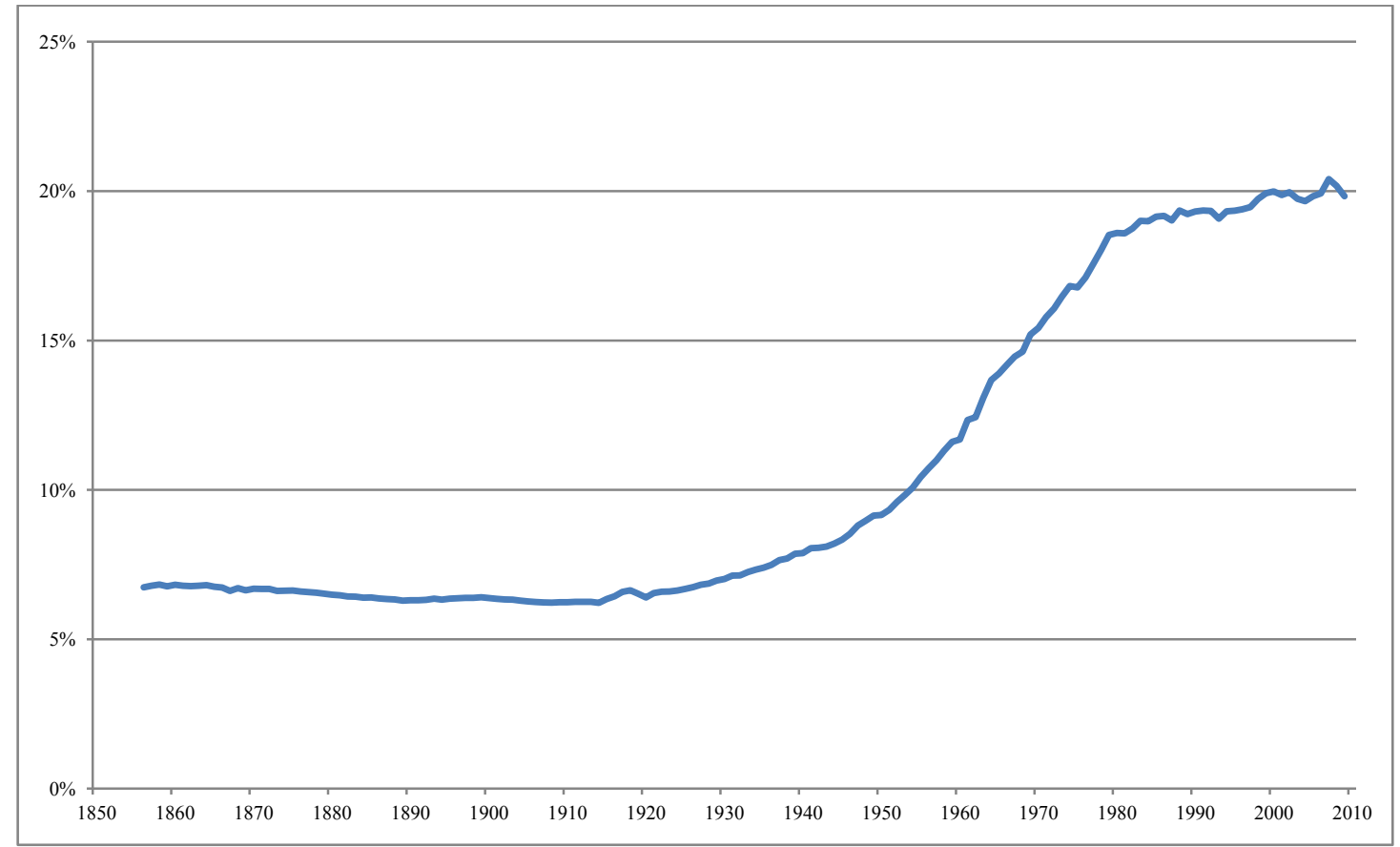

Figure 9. Aggregated final-to-useful second-law efficiency in Portugal from 1856 to 2009.

Additional insight can be obtained by considering final exergy and useful work intensities, i.e., final exergy/GDP and useful work/GDP ratios, respectively. This approach implicitly assumes, like all energy intensity studies, that all energy uses are associated to economic activity. This assumption is empirically sensible as long as the ratio of economic to non-economic uses is approximately constant and conceptually sensible as long as we consider that all energy uses are indirectly supporting economic activities, even if not being directly used in them.

For this analysis, a real GDP time series is necessary. Here we use the historical GDP series recognized by the Bank of Portugal (Banco de Portugal) and published in Lains (2003) and in Maddison (2001). For the period before the mid-twentieth century, the real GDP time series is estimated using production indices based on physical quantities (with aggregation based on the relative shares of each sub-sector at a reference year), so no price index is required (real values are directly calculated, so there is no need 
to convert from nominal to real values). It is the rate of change of the production indices that is used, which has the advantage of removing the effect of different accounting conventions in different time periods.

Henriques (2011), based on the analysis of primary energy intensity for Portugal, found three main periods: 1856 - 1920, with a constant primary energy intensity; $1920-1973$, with a decrease to one third of primary energy intensity; 1973-present, with a comparative constancy of primary energy intensity. Interestingly, in the period 1920 - 1973, modern energy intensity (i.e., coal, oil and primary electricity) had no great changes, i.e., "modern energy intensity recovered its 1913 values in the mid 1970s" (Henriques, 2011, p.111). The intensity of traditional energy decreases essentially because it is growing slower than GDP. Henriques (2011) finds no Kuznets curve in energy intensity, either with total energy or with modern energy. Henriques (2011) considers as a very relevant explanatory factor the fact that during a long period household energy dominated the energy system (71\% of primary energy in 1880 ; still $60 \%$ in the 1950 s).

Figure 10 plots final exergy and useful work intensities in Portugal from 1856 to 2009 . We can identify different periods with distinct behaviours in intensity measures:

- Until 1920 - Both curves have a somewhat decreasing trend, because efficiency remained almost constant over this period.

- From 1920 to 1950 - A slight improvement in aggregate efficiencies, together with an accelerated decrease in final exergy intensity and a stable trend in useful work intensity, shows a reduction in the demand for exergy resources to each unit of GDP.

- From 1950 to 1980 - The period of fast electrification and efficiency improvements promoted a sharp reduction in the exergy intensity. This decreasing path was interrupted in the 1960's as a consequence of the most significant industrialization period in Portugal ${ }^{12}$. Useful work intensity also slightly decreases until 1970, but dramatically increases during the 1970's, mainly motivated by two factors: (i) a very fast demographic transformation, with the resident population increasing from 8.6 millions in 1974 to 9.7 millions in 1980 , as a consequence of

\footnotetext{
${ }^{12}$ Over the 1960 's, know as the second industrialization era in Portugal, industrial value-added increased from $38 \%$ to $51 \%$ of the GDP (Lains, 2003)
} 
the democratic revolution and the decolonization process; (ii) a significant increase in the use of electricity-powered goods (Table 5) as well as the popularization of individual cars, intensifying the domestic (recreational and non-productive) energy uses. These two factors, motivated an increase in non-productive energy uses and a consequent increase in the useful work consumed that outstripped a modest GDP growth, are demonstrated by: (i) a higher average annual growth rate in residential exergy consumption (8.4\%) compared to the total final exergy consumption (5.2\%); (ii) an increase in the share of gasoline in total road transport consumption (from $39 \%$ to $59 \%$ ) over the period from 1974 to 1980 , with a corresponding increase in useful work intensity of $0.05 \mathrm{MJ} / €$.

- From 1980 onwards - Final exergy and useful work intensities stayed almost constant, whereas the aggregate efficiency increased only slightly.

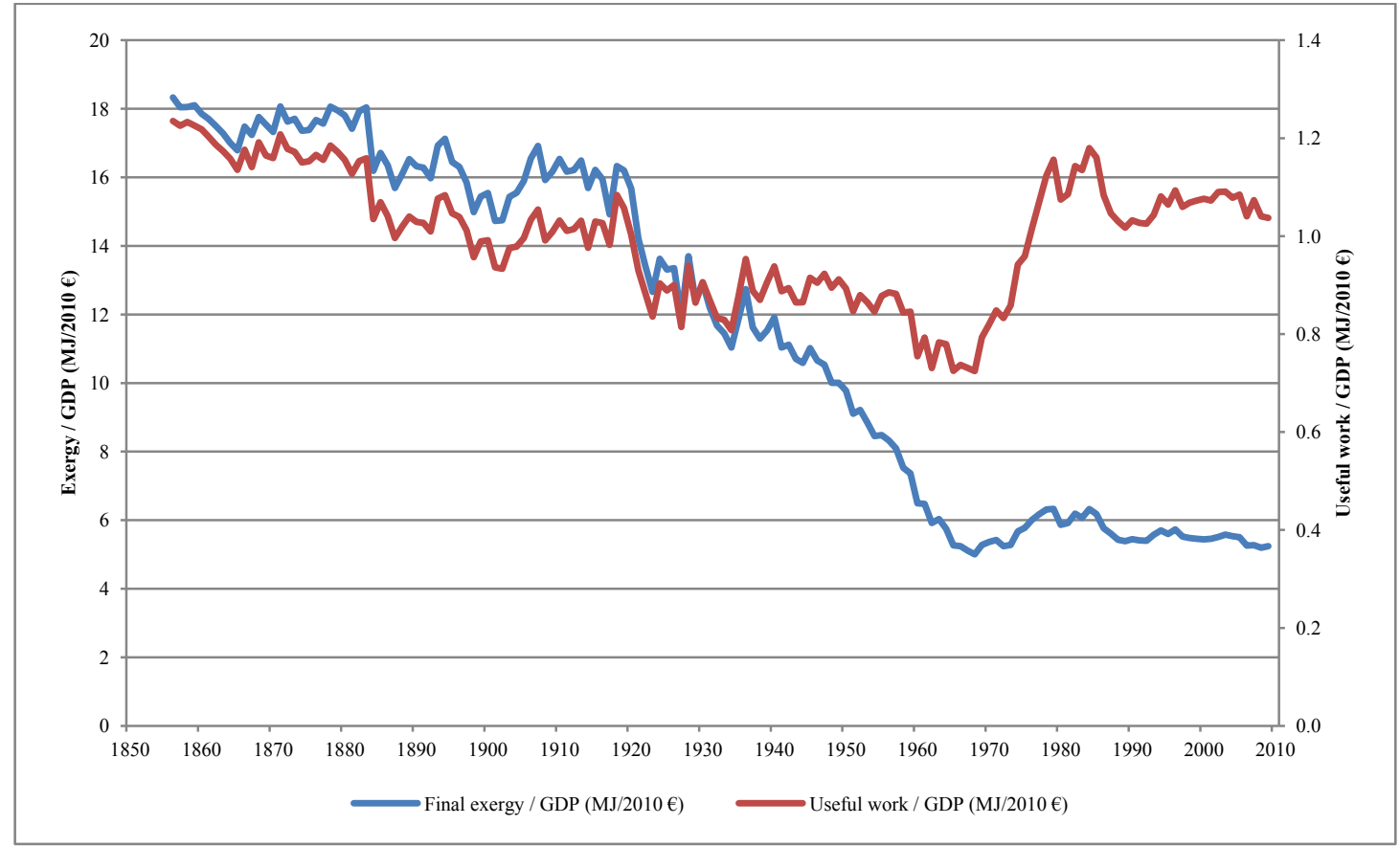

Figure 10. Exergy intensity and useful work intensity in Portugal from 1856 to 2009.

So, the main difference regarding energy transitions that our final and useful exergy analysis brings, compared to primary energy, is regarding the period 1920 - 1973, which we can split in two: (i) 1920 1950 , when there is an a reduction of primary and final energy intensities as a consequence of an improvement in final-to-useful efficiencies, and (ii) 1950 - 1973, when there is a change in the structure of energy uses. 
In Figure $11^{13}$ and Figure 12 the primary exergy ${ }^{14}$ and useful work intensities of Portugal are compared with previous country-level useful work analyses (Warr et al., 2010). Exergy intensities show a quite common decreasing trend. However, useful work intensities (Figure 12) tell a different story.

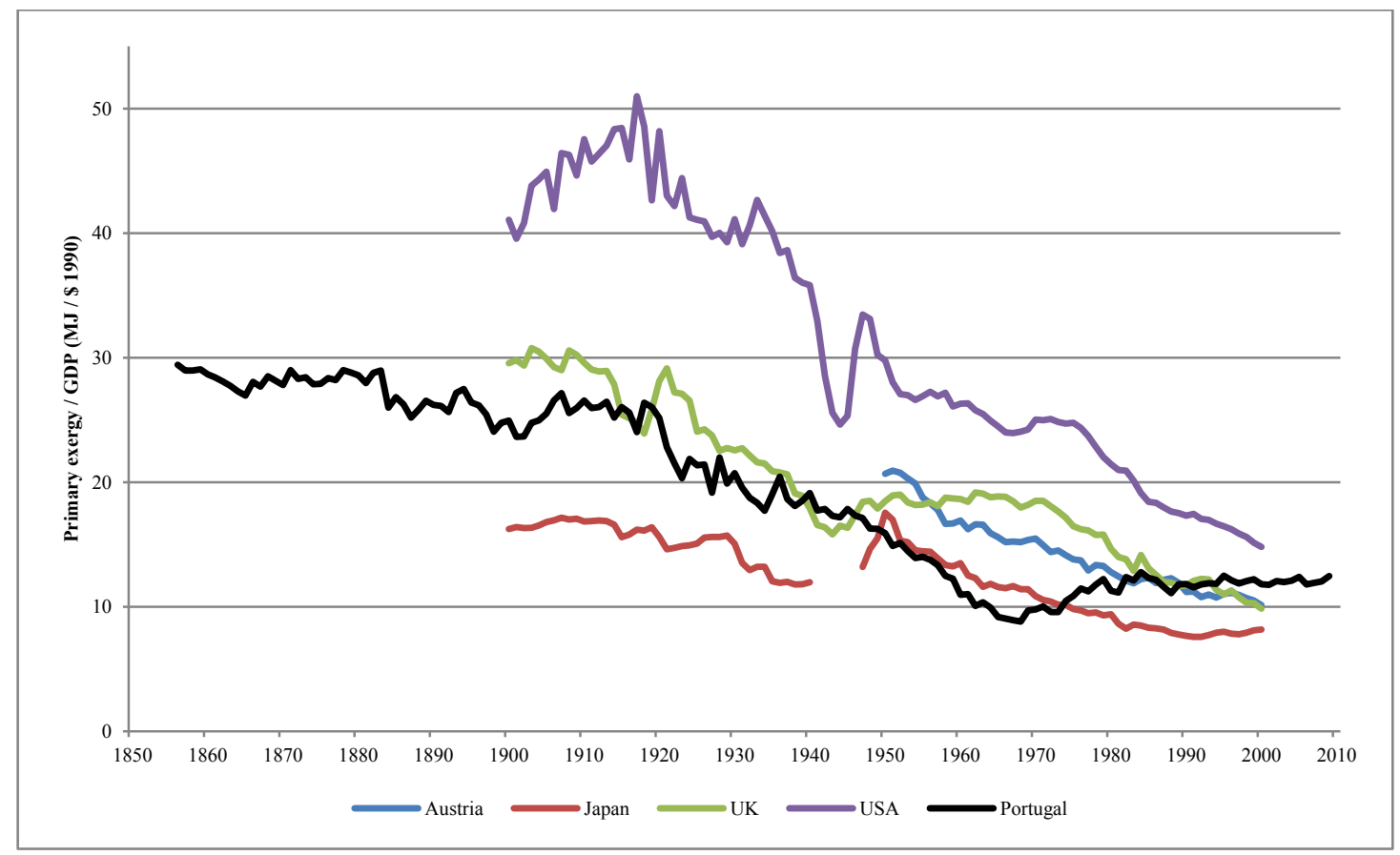

Figure 11. Primary exergy intensity across Portugal, UK, USA, Austria and Japan.

\footnotetext{
${ }^{13}$ In this figure we show primary exergy instead of final exergy to allow a direct comparison to primary exergy estimation in previous useful work analyses.

${ }^{14}$ Primary/final exergy and energy intensities exhibit a similar path, because they only differ in an aggregate coefficient, the exergy factor, which is close to 1 .
} 


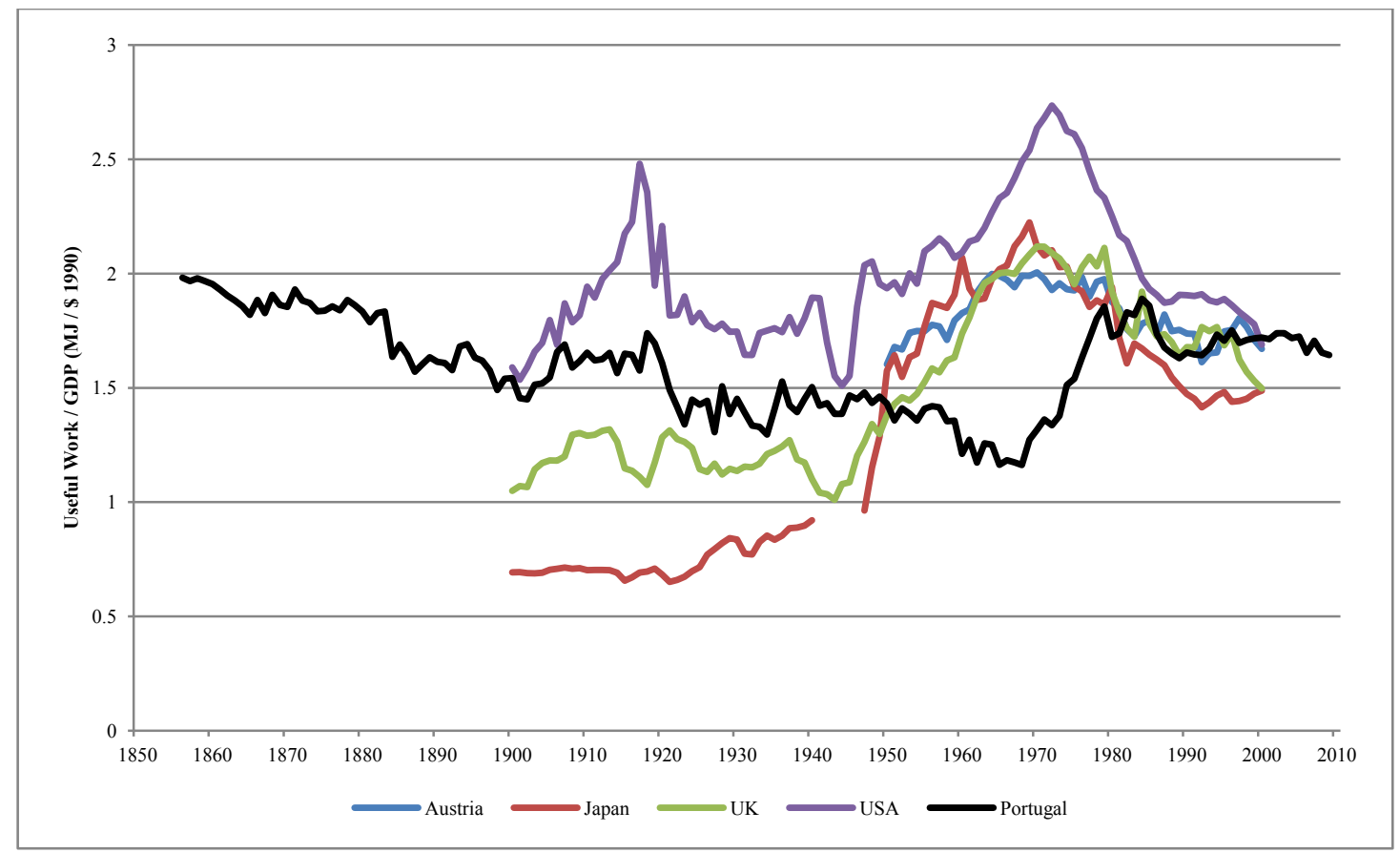

Figure 12. Useful work intensity across Portugal, UK, USA, Austria and Japan.

Table 6 shows the primary exergy and useful work intensities' trends of these countries, using the Prais-Winsten estimation method. Judged by the coefficients of determination and the tests of significance, there is a ceteris paribus evidence of a decreasing time trend of primary exergy intensities across the 5 countries, while for the useful work intensities the hypothesis of absence of a time trend cannot be rejected for any country at the level of significance of $5 \%$. On the one hand, this result confirms a decreasing demand for energy (or exergy) resources per unit of GDP, simultaneously with important efficiency gains. On the other hand, the useful work intensities capture changes in patterns of energy use, since useful work accounts for satisfied energy needs, contrarily to primary exergy that accounts for resource inputs. 
Table 6. Estimated relationships of intensity measures in countries, using the Prais-Winsten method. The explanatory variable is the time $(t)$, and the dependent variable is either the primary exergy intensity $\left(P B I_{t}\right)$ or the useful work intensity $\left(U W I_{t}\right)$; $R^{2}$ is the coefficient of determination; Standard error of the estimate is given in parentheses.

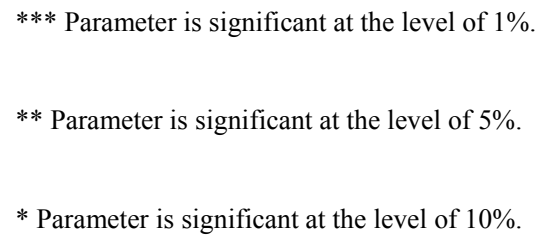

\begin{tabular}{|c|c|c|c|c|}
\hline \multirow{2}{*}{ Country } & \multicolumn{2}{|c|}{ Primary exergy intensity } & \multicolumn{2}{|c|}{ Useful work intensity } \\
\hline & Estimated relationships & Goodness of fit & Estimated relationships & Goodness of fit \\
\hline Austria (1950-2000) & $\begin{array}{c}P B I_{t}=420.4^{* * *}-0.205^{* * *} t+\varepsilon_{t} \\
(41.2) \quad(0.0208)\end{array}$ & $R^{2} \mathrm{adj} .=0.91$ & $U W I_{t}=\underset{(6.74)}{1.31}+0.0002 t+\varepsilon_{t}$ & $R^{2}$ adj. $=0.63$ \\
\hline USA (1900-2000) & $\begin{array}{c}P B I_{t}=669.3^{* * *}-0.327^{* * *} t+\varepsilon_{t} \\
(55.0)\end{array}$ & $R^{2}$ adj. $=0.70$ & $U W I_{t}=-2.23+0.0021 t+\varepsilon_{t}$ & $R^{2}$ adj. $=0.13$ \\
\hline UK (1900-2000) & $\begin{array}{c}P B I_{t}=397.3^{* * *}-0.194^{* * *} t+\varepsilon_{t} \\
(45.7) \quad(0.0235)\end{array}$ & $R^{2} \mathrm{adj} .=0.69$ & $\begin{array}{c}U W I_{t}=-9.00+0.0053 t+\varepsilon_{t} \\
(7.17)(0.0037)\end{array}$ & $R^{2}$ adj. $=0.07$ \\
\hline
\end{tabular}

Excluding Portugal, useful work intensities grew significantly after the II World War, peaking almost synchronously and exhibit a turning point around 1970 (Warr et al., 2010), mostly due to a significant increase in electricity-powered goods and the popularization of individual cars and consequently a sharp increase in passenger transport. This process took place in Portugal later. On the one hand, Portugal industrialized and opened its economy later, during the 1960's; these are the two main factors that explain the accelerated economic growth in this decade (Lains and Ferreira da Silva, 2005). On the other hand, Portuguese colonial war (1961 - 1974) led to a decrease in the useful work intensity, similar to what had occurred in the UK and USA during the II World War, due to a war economy that promoted a cutback of all non-productive energy uses.

The deindustrialization process that started in Portugal by the 1980's, and by the 1970's in the other countries, promoted significant changes in the uses of energy: less useful work for high temperature heat (from 18.5\%/16 PJ in 1980 to 7.8\%/13.7 PJ in 2009) and stationary power uses, and an increasing share of transport and other electric uses. This transition to a service economy led to a decrease in useful work intensities and a stagnation in second-law efficiencies, more pronounced in the most 
industrialized countries, as a consequence of replacing very efficient high temperature heat uses (about 47\%) for individual cars (about 13\%) and lower temperature heat uses (about 9-26\%).

\section{Conclusions}

Useful work is an exergy assessment that situates the analysis at the level of satisfied needs, after all processes of energy transformation and conversion. In this paper, we present a useful work accounting methodology that considers final-to-useful efficiencies for all energy uses, enabling a better characterization of the energy end-uses. This required refining the methodology used in previous analyses regarding the treatment of electricity. Previous works considered an aggregate electricity enduse efficiency (for the USA), neglecting differences in final-to-useful electrical conversions. We consider separately final-to-useful efficiencies of electricity end-uses in the relevant useful work categories: heat (low, medium, and high temperature), mechanical drive (electric motors), light, and other electric uses. This distinction turns out to be extremely relevant, since sectoral structure in Portugal is very different from the USA along most of the period considered (e.g., the share of industry in economic activity) and since the efficiencies in the several useful work categories are quite different.

The long-term analysis of energy uses presented in this paper implied the use of historical energy data and the estimation of missing data and efficiencies for several technical components of the energy system. However, rigorous data for estimating conversion efficiencies and energy end-use allocation are not available from the IEA energy balances or any other major energy datasets. Besides, neither the IEA nor other major energy dataset publishers provide any uncertainty analysis. This makes it impossible to do any formal accuracy assessment, a problem that has also been acknowledged by other energy analyses (e.g. Cullen and Allwood, 2010). Notwithstanding, these are currently the best available energy data that can be used to provide a picture of the historical trends.

The interpretation of the structure and dynamics of the Portuguese useful work in the very-long term allowed for a better understanding of the importance of useful work accounting and its sensitivity to structural changes in the way energy is used and how it is related with the economic growth process. This paper presents a useful work accounting for Portugal from 1856 to 2009, assessing the energy transitions in terms of energy vectors and types of uses, and the interpretation of the relation between energy use and economic growth across the entire transition from a rural society to a service economy, 
exploring the corresponding sectoral and structural transitions. In Portugal, the final exergy mix has significantly changed since 1856. A transition from biomass products to fossil fuels and electricity took place. Also, the useful work by types of use has changed from 1856 to 2009, accompanying the major structural changes in the demand for energy services. Such structural changes were promoted by the introduction of new energy vectors and the consequent changes in the final exergy mix. Such transition and technological progress fostered the improvements in final-to-useful conversion efficiencies.

In Portugal, the aggregate final-to-useful efficiency remained essentially unchanged until the end of the agricultural economy, in spite of important changes in energy vectors (mainly an important substitution of firewood for coal until WWI). The main efficiency improvements occurred due to electrification and industrialization, from 1950 to 1980 . A recent transition to a service economy, resulting from the offshoring of heavy industries and consequent deindustrialization, has contributed to a stagnation of aggregate efficiencies. For Portugal from a pre- to a post-industrial economy and in contrast to conventional intensity measures, the useful work intensity (useful work / GDP) does not exhibit a significant time trend. The same result was obtained for other five countries (Table 6). A more detailed analysis can be found in Serrenho et al. (2014).

Recent decoupling literature (UNEP, 2011) acknowledges the need for reducing the level of resource utilization per unit of GDP, which, regarding energy, represents a reduction of the primary energy (or exergy) intensity. Such economic intensity may be achieved by increasing primary-to-final efficiency, final-to-useful efficiency and/or by decreasing useful work intensity, as expressed by eq. (14).

$$
\frac{\text { Primary exergy }}{\text { GDP }}=\frac{\text { Primary exergy }}{\text { Final exergy }} \frac{\text { Final exergy }}{\text { Useful work }} \frac{\text { Useful work }}{\text { GDP }}
$$

The results obtained, namely (1) the inexistence of a time trend concerning useful work intensity and (2) the recent stagnation of the aggregate thermodynamic efficiency, suggest that further reductions in primary energy (or exergy) intensity may only be achieved:

- $\quad$ by increasing primary-to-final efficiency, subject to thermodynamic limits. However, recent efficiency stagnation suggests that future useful work increases, associated with higher demand for energy services, may only be provided with higher consumption of final exergy and energy resources, rather than efficiency improvements. 
- by structural changes that reduce the useful work intensity. However, the inexistence of a significant time trend concerning the useful work intensity supports the need to focus the debate on the scale of growth, rather than the reliance on relative decoupling to achieve sustainability (e.g. Jackson, 2009).

\section{Acknowledgments}

We acknowledge the support of FCT through PhD grant SFRH/BD/46794/2008 to André Cabrera Serrenho and through project PETE (PTDC/AMB/64762/2006). We also acknowledge the support of AdI through project Energy Wars (QREN7929).

The majority of the work by André Cabrera Serrenho was done whilst at IN+, Centre for Innovation, Technology and Policy Research, Department of Mechanical Engineering, Instituto Superior Técnico, Universidade de Lisboa. 


\section{References}

Apergis, N., Payne, J.E., 2010. Renewable energy consumption and economic growth: evidence from a panel of OECD countries. Energy Policy 38, 656-660.

Ayres, R.U., 2008. Sustainability economics: Where do we stand? Ecological Economics 67, 281-310.

Ayres, R.U., Ayres, L.W., Pokrovsky, V., 2005. On the efficiency of US electricity usage since 1900. Energy 30, 1092-1145.

Ayres, R.U., Ayres, L.W., Warr, B., 2003. Exergy, power and work in the US economy, 1900-1998. Energy 28, 219-273.

Ayres, R.U., Warr, B., 2005. Accounting for growth: the role of physical work. Structural Change and Economic Dynamics 16, 181-209.

Ayres, R.U., Warr, B., 2010. The Economic Growth Engine: How energy and work drive material prosperity. Edward Elgar Publishing, Cheltenham, UK.

Chen, B., Chen, G.Q., 2006. Exergy analysis for resource conversion of the Chinese Society 1993 under the material product system. Energy 31, 1115-1150.

Chen, B., Chen, G.Q., 2007a. Resource analysis of the Chinese society 1980-2002 based on exergy-Part 2: Renewable energy sources and forest. Energy Policy 35, 2051-2064.

Chen, B., Chen, G.Q., 2007b. Resource analysis of the Chinese society 1980-2002 based on exergy-Part 3: Agricultural products. Energy Policy 35, 2065-2078.

Chen, B., Chen, G.Q., 2007c. Resource analysis of the Chinese society 1980-2002 based on exergy-Part 4: Fishery and rangeland. Energy Policy 35, 2079-2086.

Chen, G.Q., Chen, B., 2007d. Resource analysis of the Chinese society 1980-2002 based on exergy-Part 1: Fossil fuels and energy minerals. Energy Policy 35, 2038-2050.

Chen, G.Q., Qi, Z.H., 2007. Systems account of societal exergy utilization: China 2003. Ecological Modelling 208, 102-118.

Chontanawat, J., Hunt, L.C., Pierse, R., 2008. Does energy consumption cause economic growth?: Evidence from a systematic study of over 100 countries. Journal of Policy Modeling 30, 209-220.

Cullen, J.M., Allwood, J.M., 2010. Theoretical efficiency limits for energy conversion devices. Energy 35, 2059-2069.

Dai, J., Chen, B., Sciubba, E., 2014. Ecological Accounting Based on Extended Exergy: A Sustainability Perspective. Environmental Science \& Technology 48, 9826-9833.

DGGE, 2004. Eficiência energética em equipamentos e sistemas eléctricos no sector residencial. Direcção-Geral de Geologia e Energia, Lisboa, Portugal.

DGSE, 1929-1984. Estatística das Instalações Eléctricas em Portugal, 1929-1984. Direcção-Geral dos Serviços Eléctricos, Lisboa, Portugal.

EIA, 2006. Manufacturing Energy Consumption Survey (1991, 1994, 1998, 2006). U.S. Energy Information Administration.

Ertesvåg, I.S., Mielnik, M., 2000. Exergy analysis of the Norwegian society. Energy 25, 957-973. 
FAO, 2011. FAOSTAT. Food and Agriculture Organization of the United Nations, Rome, Italy.

Ford, K.W., Rochlin, G.I., Socolow, R.H., Hartley, D.L., Hardesty, D.R., Lapp, M., Dooher, J., Dryer, F., Berman, S.M., Silverstein, S.D., Ross, M., 1975. Efficient Use of Energy. American Institute of Physics, New York, USA.

Fouquet, R., 2008. Heat, Power and Light. Revolutions in Energy Services. Edward Elgar, Cheltenham, UK.

Fouquet, R., Pearson, P.J.G., 2006. Seven centuries of energy services: the price and use of light in the United Kingdom (1300-2000). The Energy Journal 27, 139-177.

Gasparatos, A., El-Haram, M., Horner, M., 2009a. Assessing the sustainability of the UK society using thermodynamic concepts: Part 1. Renewable and Sustainable Energy Reviews 13, 1074-1081.

Gasparatos, A., El-Haram, M., Horner, M., 2009b. Assessing the sustainability of the UK society using thermodynamic concepts: Part 2. Renewable and Sustainable Energy Reviews 13, 956-970.

Gasparatos, A., El-Haram, M., Horner, M., 2009c. A longitudinal analysis of the UK transport sector, 1970-2010. Energy Policy 37, 623-632.

Grübler, A., Nakićenović, N., 1996. Decarbonizing the global energy system. Technological Forecasting and Social Change 53, 97-110.

Hammond, G.P., Stapleton, A.J., 2001. Exergy analysis of the United Kingdom energy system. Proceedings of the Institution of Mechanical Engineers, Part A: Journal of Power and Energy 215, 141 162.

Henriques, S.T., 2006. Os Consumos Domésticos de Energia em Portugal, M.Sc. Thesis on Economics and Policy of Energy and Environment. Instituto Superior de Economia e Gestão, Technical University of Lisbon, Lisboa, Portugal.

Henriques, S.T., 2011. Energy Transitions, Economic Growth and Structural Change - Portugal in a Long-run Comparative Perspective, Lund Studies in Economic History 54. Lund University, Lund, Sweden.

Heywood, J.B., 1988. Internal Combustion Engine Fundamentals. McGraw-Hill, New York, USA.

IEA, 2011a. Energy Balances of OECD Countries, Documentaion for Beyond 2020 Files. International Energy Agency, Paris, France.

IEA, 2011b. Energy Statistics of OECD Countries, Documentation for Beyond 2020 Files. International Energy Agency, Paris, France.

IGIL, 1856-2007. Anais do Instituto Geofísico do Infante D. Luís. Instituto Geofísico do Infante D. Luiz, Lisboa, Portugal.

INE, 1875-2009. Anuário Estatístico de Portugal. Instituto Nacional de Estatística, Lisboa, Portugal.

INE, 1941-1960. Estatísticas Industriais. Instituto Nacional de Estatística, Lisboa, Portugal.

INE, 1970. Inquérito aos Orçamentos Familiares, 1967/1968. Instituto Nacional de Estatística, Lisboa, Portugal.

INE, 1976. Inquérito aos Orçamentos Familiares, 1973/1974. Instituto Nacional de Estatística, Lisboa, Portugal.

INE, 1983. Inquérito aos Orçamentos Familiares, 1980/1981. Instituto Nacional de Estatística, Lisboa, Portugal. 
INE, 1987-1997. Indicadores de Conforto das Famílias. Instituto Nacional de Estatística, Lisboa, Portugal.

INE, 1992. Inquérito aos Orçamentos Familiares, 1989/1990. Instituto Nacional de Estatística, Lisboa, Portugal.

INE, 1997. Inquérito aos Orçamentos Familiares, 1994/1995. Instituto Nacional de Estatística, Lisboa, Portugal.

INE, 2002. Inquérito aos Orçamentos Familiares, 2000. Instituto Nacional de Estatística, Lisboa, Portugal.

INE, 2008. Inquérito às Despesas das Famílias, 2005/2006. Instituto Nacional de Estatística, Lisboa, Portugal.

INE, 2010. Inquérito ao Consumo de Energia no Sector Doméstico 2010. Instituto Nacional de Estatística, Lisboa, Portugal.

Jackson, T., 2009. Prosperity without Growth: Economics for a Finite Planet. Earthscan, New York, NY, USA.

Joyce, W.H., 1991. Energy Consumption Spirals Downward in the Polyolefins Industry, in: Tester, J.W., Wood, D.O., Ferrari, N.A. (Eds.), Energy and the Environment in the 21st Century. Proceedings of the Conference held at the Massachusetts Institute of Technology, March 26-28, 1990. The MIT Press, Cambridge, MA, USA.

Krausmann, F., Gingrich, S., Eisenmenger, N., Erb, K.-H., Haberl, H., Fischer-Kowalski, M., 2009. Growth in global materials use, GDP and population during the 20th century. Ecological Economics 68 , 2696-2705.

Kümmel, R., Strassl, W., Gossner, A., Eichhorn, W., 1985. Technical progress and energy dependent production functions. Journal of Economics 45, 285-311.

Lains, P., 2003. Os Progressos do Atraso. Uma Nova História Económica de Portugal. Imprensa de Ciências Sociais, Viseu, Portugal.

Lains, P., Ferreira da Silva, Á., 2005. História Económica de Portugal, 1700-2000. Imprensa de Ciências Sociais, Viseu, Portugal.

Maddison, A., 2001. The World Economy - A Millennial Perspective. Organisation for Economic Cooperation and Development, Paris, France.

Miketa, A., Mulder, P., 2005. Energy productivity across developed and developing countries in 10 manufacturing sectors: patterns of growth and convergence. Energy Economics 27, 429-453.

Milia, D., Sciubba, E., 2006. Exergy-based lumped simulation of complex systems: An interactive analysis tool. Energy 31, 100-111.

Moran, M.J., Shapiro, H.N., 2004. Fundamentals of Engineering Thermodynamics, 5th ed. John Wiley \& Sons, Sussex, England.

Mulder, P., Groot, H.L.F.D., 2007. Sectoral energy- and labour-productivity convergence. Environmental \& Resource Economics 36, 85-112.

Nakicenovic, N., Gilli, P.V., Kurz, R., 1996. Regional and global exergy and energy efficiencies. Energy 21, 223-237.

Nordhaus, W.D., 1998. Do real-output and real-wage measures capture reality? The history of lighting suggests not, Cowles Foundation for Research in Economics at Yale University, New Haven, CT, USA. 
Ptasinski, K.J., Koymans, M.N., Verspagen, H.H.G., 2006. Performance of the Dutch Energy Sector based on energy, exergy and Extended Exergy Accounting. Energy 31, 3135-3144.

Reistad, G., 1975. Available Energy Conversion and Utilization in the United States. Journal of Engineering for Power - Transactions of the ASME 97, 429-434.

Rocco, M.V., Colombo, E., Sciubba, E., 2014. Advances in exergy analysis: a novel assessment of the Extended Exergy Accounting method. Applied Energy 113, 1405-1420.

Rosen, M.A., Bulucea, C.A., 2009. Using exergy to understand and improve the efficiency of electrical power technologies. Entropy 11, 820-835.

Ross, M., 1997. Fuel efficiency and the physics of automobiles. Contemporary Physics 36, 381-394.

Schandl, H., Fischer-Kowalski, M., Grunbuhel, C., Krausmann, F., 2009. Socio-metabolic transitions in developing Asia. Technological Forecasting \& Social Change 76, 267-281.

Sciubba, E., Wall, G., 2007. A brief commented history of exergy from beginning to 2004. International Journal of Thermodynamics 10, 1-26.

Seckin, C., Sciubba, E., Bayulken, A.R., 2013. Extended exergy analysis of Turkish transportation sector. Journal of Cleaner Production 47, 422-436.

Serrenho, A.C., Sousa, T., Warr, B., Ayres, R.U., Domingos, T., 2014. Decomposition of useful work intensity: The EU (European Union)-15 countries from 1960 to 2009. Energy 76, 704-715.

Smil, V., 1991. General Energetics: Energy in the Biosphere and Civilization. John Wiley \& Sons, USA.

Smil, V., 1994. Energy in World History. Westview Press, Boulder, CO, USA.

Smil, V., 2001. Enriching the Earth: Fritz Haber, Carl Bosch, and the Transformation of World Food Production. The MIT Press, Cambridge, MA, USA.

Steinberger, J.K., Krausmann, F., 2011. Material and energy productivity. Environmental Science \& Technology 45, 1169-1176.

Stern, D.I., 1993. Energy and economic growth in the USA: A multivariate approach. Energy Economics 15, 137-150.

Stern, D.I., 2004. Economic growth and energy, in: Cutler, J.C. (Ed.), Encyclopedia of Energy. Elsevier, New York, NY, USA, pp. 35-51.

Stern, D.I., 2010. Energy quality. Ecological Economics 69, 1471-1478.

Stern, D.I., Cleveland, C.J., 2004. Energy and economic growth, Rensselaer Polytechnic Institute, New York, NY, USA.

Szargut, J., Morris, D.R., Steward, F.R., 1988. Exergy Analysis of Thermal, Chemical, and Metallurgical Processes. Hemisphere Publishing Corporation, Berlin, Germany.

UNEP, 2011. Decoupling Natural Resource Use and Environmental Impacts from Economic Growth. United Nations Environment Programme.

Wall, G., 1987. Exergy conversion in the Swedish society. Resources and Energy 9, 55-73.

Wall, G., 1990. Exergy conversion in the Japanese society. Energy 15, 435-444.

Wall, G., Scuibba, E., Naso, V., 1994. Exergy use in the Italian society. Energy 19, 1267-1274. 
Warr, B., Ayres, R.U., 2006. REXS: A forecasting model for assessing the impact of natural resource consumption and technological change on economic growth. Structural Change and Economic Dynamics 17, 329-378.

Warr, B., Ayres, R.U., 2010. Evidence of causality between the quantity and quality of energy consumption and economic growth. Energy 35, 1688-1693.

Warr, B., Ayres, R.U., Eisenmenger, N., Krausmann, F., Schandl, H., 2010. Energy use and economic development: A comparative analysis of useful work supply in Austria, Japan, the United Kingdom and the US during 100 years of economic growth. Ecological Economics 69, 1904-1917.

Warr, B., Schandl, H., Ayres, R.U., 2008. Long term trends in resource exergy consumption and useful work supplies in the UK, 1900 to 2000. Ecological Economics 68, 126-140.

Williams, E., Warr, B., Ayres, R.U., 2008. Efficiency dilution: long-term exergy conversion trends in Japan. Environmental Science \& Technology 42, 4964-4970.

Wirsenius, S., 2000. Human Use of Land and Organic Materials: Modeling the Turnover of Biomass in the Global Food System, PhD thesis, Department of Physucal Resource Theory, Chalmers University of Technology and Goteborg University, Göteborg, Sweden. 
Appendices

A. Allocation of useful work categories with IEA energy balances

(1960-2009)

\begin{tabular}{|c|c|c|c|c|}
\hline & Sector & Ene & carrier & Useful work category \\
\hline Energy sector & Coal mines & Coal products & & Medium temperature heat \\
\hline own uses & & Oil products & Gas/diesel oil & Mechanical drive \\
\hline & Oil and gas extraction & Oil products & $\begin{array}{l}\text { Gas/diesel oil } \\
\text { LPG }\end{array}$ & $\begin{array}{l}\text { Mechanical drive } \\
\text { Mechanical drive }\end{array}$ \\
\hline & Oil refineries & Oil products & & Medium temperature heat \\
\hline & & Natural gas & & Medium temperature heat \\
\hline & Gas works & Coal products & & High temperature heat \\
\hline & & Natural gas & & High temperature heat \\
\hline & Coke ovens & Coal products & & High temperature heat \\
\hline & & Natural gas & & High temperature heat \\
\hline & Patent fuel plants & Coal products & & Medium temperature heat \\
\hline & Other non-specified & Oil products & $\begin{array}{l}\text { Bitumen } \\
\text { Gas/diesel oil }\end{array}$ & $\begin{array}{l}\text { Low temperature heat } \\
\text { Mechanical drive }\end{array}$ \\
\hline Industry & Iron and steel & Coal products & & High temperature heat \\
\hline & & Oil products & Gas/diesel oil & Mechanical drive \\
\hline & & & Fuel oil & High temperature heat \\
\hline & & & LPG & High temperature heat \\
\hline & & Natural gas & & High temperature heat \\
\hline & $\begin{array}{l}\text { Chemical and } \\
\text { petrochemical }\end{array}$ & Coal products & & $\begin{array}{l}50 \% \text { High temperature heat } \\
50 \% \text { Medium temperature heat }\end{array}$ \\
\hline & & Oil products & Gas/diesel oil & Mechanical drive \\
\hline & & & Fuel oil & $50 \%$ High temperature heat \\
\hline & & & $\begin{array}{l}\text { LPG } \\
\text { Non-snecified }\end{array}$ & $50 \%$ Medium temperature heat \\
\hline & & Natural gas & Non-specinted & $50 \%$ High temperature heat \\
\hline & & & & $50 \%$ Medium temperature heat \\
\hline & & $\begin{array}{l}\text { Combustible } \\
\text { renewables }\end{array}$ & Industrial waste & High temperature heat \\
\hline & & & Solid biofuels & Low temperature heat \\
\hline & Non-ferrous metals & Coal products & & $50 \%$ High temperature heat \\
\hline & & & & $50 \%$ Medium temperature heat \\
\hline & & Oil products & Gas/diesel oil & Mechanical drive \\
\hline & & & Fuel oil & $50 \%$ High temperature heat \\
\hline & & & LPG & $50 \%$ Medium temperature heat \\
\hline & & Natural gas & & $\begin{array}{l}50 \% \text { High temperature heat } \\
50 \% \text { Medium temperature heat }\end{array}$ \\
\hline & & $\begin{array}{l}\text { Combustible } \\
\text { renewables }\end{array}$ & Solid biofuels & Low temperature heat \\
\hline & Non-metallic minerals & Coal products & & High temperature heat \\
\hline & & Oil products & Gas/diesel oil & Mechanical drive \\
\hline & & & Fuel oil & $50 \%$ High temperature heat \\
\hline & & & LPG & $50 \%$ Medium temperature heat \\
\hline & & & Petroleum coke & \\
\hline & & Natural gas & & $50 \%$ High temperature heat \\
\hline & & & & $50 \%$ Medium temperature heat \\
\hline & & $\begin{array}{l}\text { Combustible } \\
\text { renewables }\end{array}$ & Industrial waste & High temperature heat \\
\hline & & & Solid biofuels & Low temperature heat \\
\hline & Transport equipment & Coal products & & $\begin{array}{l}50 \% \text { High temperature heat } \\
50 \% \text { Medium temperature heat }\end{array}$ \\
\hline & & Oil products & Gas/diesel oil & Mechanical drive \\
\hline & & & Fuel oil & $50 \%$ High temperature heat \\
\hline & & & LPG & $50 \%$ Medium temperature heat \\
\hline & & Natural gas & & $50 \%$ High temperature heat \\
\hline & & & & $50 \%$ Medium temperature heat \\
\hline & Machinery & Coal products & & $50 \%$ High temperature heat \\
\hline & & & & $50 \%$ Medium temperature heat \\
\hline & & Oil products & $\begin{array}{l}\text { Gas/diesel oil } \\
\text { Motor gasoline }\end{array}$ & Mechanical drive \\
\hline & & & Fuel oil & $50 \%$ High temperature heat \\
\hline & & & LPG & $50 \%$ Medium temperature heat \\
\hline & & Natural gas & & $50 \%$ High temperature heat \\
\hline & & & & $50 \%$ Medium temperature heat \\
\hline & & $\begin{array}{l}\text { Combustible } \\
\text { renewables }\end{array}$ & Solid biofuels & Low temperature heat \\
\hline & Mining and quarrying & Oil products & Gas/diesel oil & Mechanical drive \\
\hline
\end{tabular}




\begin{tabular}{|c|c|c|c|c|}
\hline \multicolumn{2}{|r|}{ Sector } & \multicolumn{2}{|c|}{ Energy carrier } & Useful work category \\
\hline & & Natural gas & $\begin{array}{l}\text { Motor gasoline } \\
\text { Fuel oil } \\
\text { LPG }\end{array}$ & $\begin{array}{l}50 \% \text { High temperature heat } \\
50 \% \text { Medium temperature heat } \\
50 \% \text { High temperature heat } \\
50 \% \text { Medium temperature heat }\end{array}$ \\
\hline & \multirow[t]{4}{*}{ Food and tobacco } & Coal products & & Low temperature heat \\
\hline & & Oil products & $\begin{array}{l}\text { Gas/diesel oil } \\
\text { Motor gasoline } \\
\text { Kerosene } \\
\text { Fuel oil } \\
\text { LPG } \\
\end{array}$ & $\begin{array}{l}\text { Mechanical drive } \\
\text { Mechanical drive } \\
\text { Low temperature heat } \\
\text { Low temperature heat } \\
\text { Low temperature heat }\end{array}$ \\
\hline & & Natural gas & & Low temperature heat \\
\hline & & $\begin{array}{l}\text { Combustible } \\
\text { renewables }\end{array}$ & Solid biofuels & Low temperature heat \\
\hline & \multirow[t]{3}{*}{ Paper, pulp and print } & Oil products & $\begin{array}{l}\text { Gas/diesel oil } \\
\text { Fuel oil } \\
\text { LPG }\end{array}$ & $\begin{array}{l}\text { Mechanical drive } \\
\text { Low temperature heat } \\
\text { Low temperature heat }\end{array}$ \\
\hline & & Natural gas & & Low temperature heat \\
\hline & & $\begin{array}{l}\text { Combustible } \\
\text { renewables }\end{array}$ & Solid biofuels & Low temperature heat \\
\hline & \multirow[t]{3}{*}{ Wood and wood products } & Oil products & $\begin{array}{l}\text { Gas/diesel oil } \\
\text { Fuel oil } \\
\text { LPG } \\
\end{array}$ & $\begin{array}{l}\text { Mechanical drive } \\
\text { Low temperature heat } \\
\text { Low temperature heat }\end{array}$ \\
\hline & & Natural gas & & Low temperature heat \\
\hline & & $\begin{array}{l}\text { Combustible } \\
\text { renewables }\end{array}$ & Solid biofuels & Low temperature heat \\
\hline & \multirow[t]{2}{*}{ Construction } & Oil products & $\begin{array}{l}\text { Gas/diesel oil } \\
\text { LPG } \\
\text { Motor gasoline } \\
\text { Fuel oil } \\
\end{array}$ & $\begin{array}{l}\text { Mechanical drive } \\
\text { Mechanical drive } \\
\text { Mechanical drive } \\
\text { Low temperature heat }\end{array}$ \\
\hline & & Natural gas & & Low temperature heat \\
\hline & \multirow[t]{3}{*}{ Textile and leather } & Coal products & & Low temperature heat \\
\hline & & Oil products & & Low temperature heat \\
\hline & & $\begin{array}{l}\text { Combustible } \\
\text { renewables }\end{array}$ & Solid biofuels & Low temperature heat \\
\hline & \multirow[t]{3}{*}{ Other non-specified } & Coal products & & $\begin{array}{l}50 \% \text { High temperature heat } \\
50 \% \text { Medium temperature heat }\end{array}$ \\
\hline & & Natural gas & & $\begin{array}{l}50 \% \text { High temperature heat } \\
50 \% \text { Medium temperature heat }\end{array}$ \\
\hline & & $\begin{array}{l}\text { Combustible } \\
\text { renewables }\end{array}$ & Solid biofuels & Low temperature heat \\
\hline \multirow[t]{7}{*}{ Transport } & \multirow[t]{2}{*}{ Rail } & Coal products & & Mechanical drive \\
\hline & & Oil products & & Mechanical drive \\
\hline & Domestic aviation & Oil products & & Mechanical drive \\
\hline & \multirow{3}{*}{ Road } & Oil products & & Mechanical drive \\
\hline & & Natural gas & & Mechanical drive \\
\hline & & $\begin{array}{l}\text { Combustible } \\
\text { renewables }\end{array}$ & & Mechanical drive \\
\hline & Navigation & Oil products & & Mechanical drive \\
\hline \multirow[t]{15}{*}{ Other } & \multirow[t]{4}{*}{ Residential } & Coal products & & Low temperature heat \\
\hline & & Oil products & & Low temperature heat \\
\hline & & Natural gas & & Low temperature heat \\
\hline & & $\begin{array}{l}\text { Combustible } \\
\text { renewables }\end{array}$ & Solid biofuels & Low temperature heat \\
\hline & \multirow{3}{*}{$\begin{array}{l}\text { Commercial and public } \\
\text { services }\end{array}$} & Coal products & & Low temperature heat \\
\hline & & Oil products & & Low temperature heat \\
\hline & & Natural gas & & Low temperature heat \\
\hline & Agriculture/forestry & Oil products & $\begin{array}{l}\text { Gas/diesel oil } \\
\text { Motor gasoline } \\
\text { Fuel oil } \\
\text { Kerosene } \\
\text { LPG } \\
\end{array}$ & $\begin{array}{l}\text { Mechanical drive } \\
\text { Mechanical drive } \\
\text { Low temperature heat } \\
\text { Low temperature heat } \\
\text { Low temperature heat }\end{array}$ \\
\hline & \multirow[t]{2}{*}{ Fishing } & Oil products & $\begin{array}{l}\text { Gas/diesel oil } \\
\text { Motor gasoline } \\
\text { LPG } \\
\text { Fuel oil }\end{array}$ & $\begin{array}{l}\text { Mechanical drive } \\
\text { Mechanical drive } \\
\text { Low temperature heat } \\
\text { Low temperature heat }\end{array}$ \\
\hline & & Natural gas & & Low temperature heat \\
\hline & \multirow[t]{5}{*}{ Other non-specified } & Coal products & $\begin{array}{l}\text { Coke oven coke } \\
\text { Other bituminous } \\
\text { coal }\end{array}$ & $\begin{array}{l}\text { Low temperature heat } \\
\text { Low temperature heat }\end{array}$ \\
\hline & & & Gas works gas & Low temperature heat \\
\hline & & Oil products & & Low temperature heat \\
\hline & & Natural gas & & Low temperature heat \\
\hline & & $\begin{array}{l}\text { Combustible } \\
\text { renewables }\end{array}$ & & Low temperature heat \\
\hline
\end{tabular}


B. Allocation of useful work categories for the period 1856-1959

\begin{tabular}{|c|c|c|}
\hline Energy vector & Useful work category & Data sources \\
\hline \multirow{5}{*}{$\begin{array}{l}\text { Coal and coal products } \\
\text { Oil and oil products }\end{array}$} & High Temp. Heat & \multirow{4}{*}{$\begin{array}{c}\text { INE (1941-1960) } \\
\text { DGSE (1929-1984) } \\
\text { Henriques (2011) }\end{array}$} \\
\hline & Medium Temp. Heat & \\
\hline & Low Temp. Heat & \\
\hline & Mechanical drive & \\
\hline & Light & $\begin{array}{c}\text { Henriques (2011) } \\
\text { Fouquet and Pearson (2006) }\end{array}$ \\
\hline \multirow{3}{*}{ Combustible renewables } & Medium Temp. Heat & \multirow{3}{*}{ Henriques (2011) } \\
\hline & Low Temp. Heat & \\
\hline & Mechanical drive & \\
\hline \multirow{5}{*}{ Electricity } & High Temp. Heat & \multirow{5}{*}{$\begin{array}{c}\text { Ayres et al. (2005) } \\
\text { INE (1941-1960) } \\
\text { Fouquet and Pearson (2006) }\end{array}$} \\
\hline & Low Temp. Heat & \\
\hline & Light & \\
\hline & Other electric uses & \\
\hline & Mechanical drive & \\
\hline Food for humans & \multirow{2}{*}{ Muscle work } & \multirow{3}{*}{ Henriques (2011) } \\
\hline Feed for working animals & & \\
\hline Other non-conventional & Mechanical drive & \\
\hline
\end{tabular}

